DIW BERLIN

Discussion

Papers
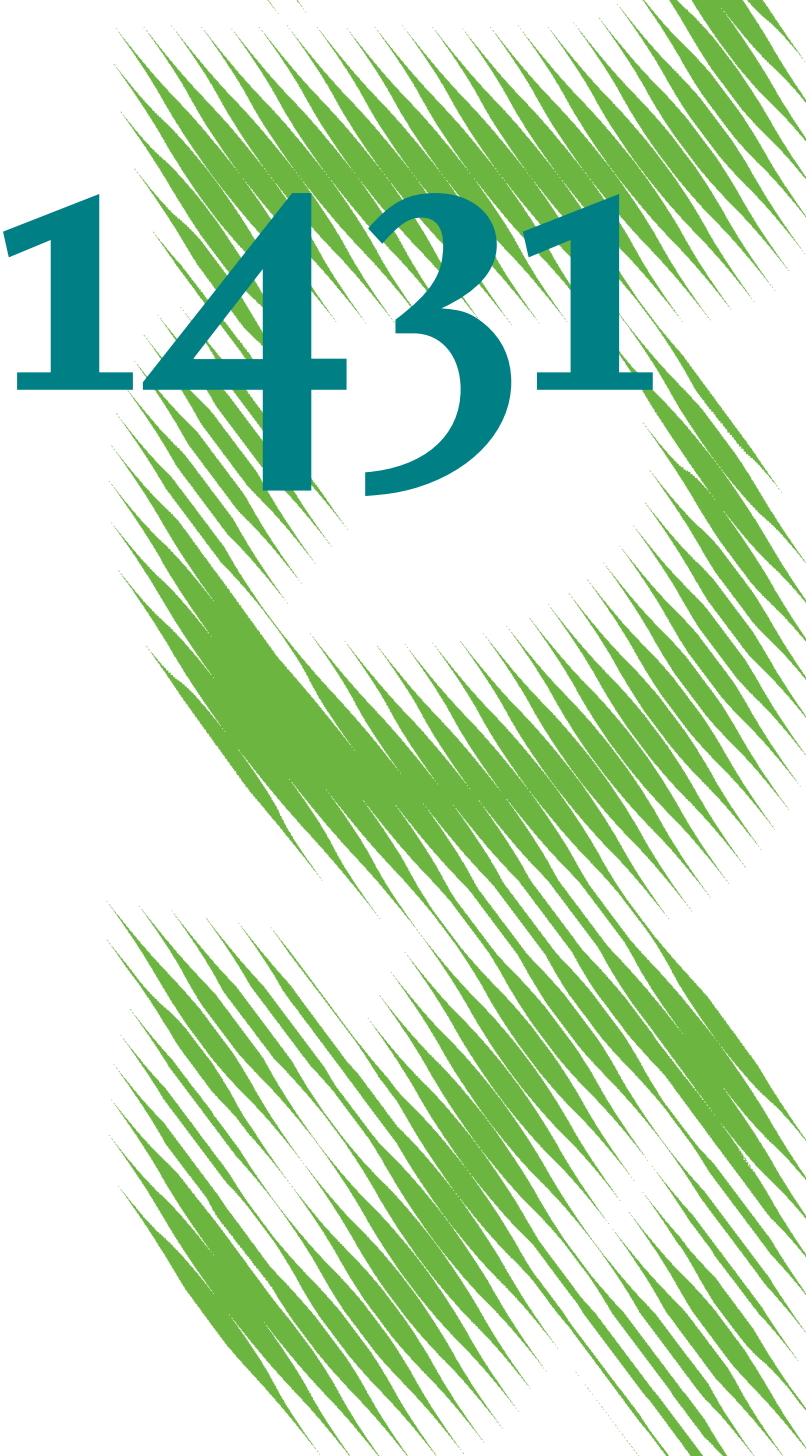

The Earnings Returns to Graduating with Honors -

Evidence from Law Graduates 
Opinions expressed in this paper are those of the author(s) and do not necessarily reflect views of the institute.

IMPRESSUM

(C) DIW Berlin, 2014

DIW Berlin

German Institute for Economic Research

Mohrenstr. 58

10117 Berlin

Tel. +49 (30) $89789-0$

Fax +49 (30) $89789-200$

http://www.diw.de

ISSN electronic edition 1619-4535

Papers can be downloaded free of charge from the DIW Berlin website:

http://www.diw.de/discussionpapers

Discussion Papers of DIW Berlin are indexed in RePEc and SSRN:

http://ideas.repec.org/s/diw/diwwpp.html

http://www.ssrn.com/link/DIW-Berlin-German-Inst-Econ-Res.html 


\title{
The Earnings Returns to Graduating with Honors - Evidence from Law Graduates
}

\author{
Ronny Freier* Mathias Schumann ${ }^{\dagger} \quad$ Thomas Siedler ${ }^{\ddagger}$ \\ October 29, 2014
}

\begin{abstract}
This paper studies the causal effects of graduating from university with an honors degree on subsequent earnings. While a rich body of literature has focused on estimating returns to human capital, few studies have analyzed returns at the very top of the education distribution. We highlight the importance of honors degrees for future labor market success in the context of German law graduates. Using a difference-in-differences research design combined with entropy balancing, we find that students of law who passed the state bar exam with an honors degree receive a significant earnings premium of about 14 percent. The results are robust to various sensitivity analyses.
\end{abstract}

Keywords: $\quad$ returns to education, difference-in-differences, entropy balancing,

JEL classification: J01, J31, J44

Acknowledgments: We thank Michael Bahrs, Iwan Barankay, Bernt Bratsberg, Frederic Döhl, Bart Goldsteyn, Luise Görges, Peter Haan, Daniel Hamermesh, Katja Maria Kaufmann, Olivier Marie, Aderonke Osikominu, M. Daniele Paserman, Annemarie Paul, Petra Persson, Torsten Santavirta, Guido Schwerdt, Gesine Stephan and Niels Westergaard-Nielsen and numerous seminar and conference participants for helpful comments and suggestions. We also thank the DZHW and, in particular, Gregor Fabian, Thomas Lewerenz, Ulrich Prigge and Torsten Rehn at DZHW for providing access to the graduate survey data and for all their support. The usual disclaimer applies.

\footnotetext{
*DIW Berlin and Free University Berlin.

${ }^{\dagger}$ Universität Hamburg.

${ }^{\ddagger}$ Universität Hamburg, University of Essex and IZA Bonn.
} 


\section{Introduction}

The majority of industrialized countries experienced massive increases in educational attainment in the twentieth century. Goldin and Katz (2010) report that among Americans born in 1930, only one in four attended college, whereas over 60 percent of the cohort born in 1970 did so. Similarly, the share of 25-64 year-olds with tertiary education has increased from 22 to 31 percent in the OECD countries in recent years (OECD, 2013). It is also well documented that university graduates fare better in the labor market than non-graduates in terms of employment, salaries, and the risk of experiencing unemployment (Blundell et al., 2000; OECD, 2013). It is, however, less known how the performance in higher education affects individual's labor market chances, and whether students with an excellent study performance are also more successful in the labor market.

How important is an outstanding study performance for graduates' labor market earnings? In particular, do students who graduate with an honors degree experience positive labor market returns later in life? The present study focuses on evaluating the causal effect of graduating with an honors degree in law in Germany on subsequent labor market earnings. The case of German law graduates is of particular interest for a number of reasons. First, students of law in Germany receive an explicit honors degree (Prädikatsexamen) if they exceed a grade threshold of nine points in the overall grade point average (on a scale of 0 to 18). Second, in our observation period, the final examination was the responsibility of state law examination departments (and not of the universities), which makes the law degrees comparable. While the exact examination rules vary slightly by state, the honors degree status is generally accepted and students of law are free to work throughout Germany. Third, anecdotal evidence points to the major importance of the honors degree in determining future labor market outcomes. Both in the public and private sectors, an honors degree is often the explicit entrance requirement to positions of high responsibility and prestige.

The economic literature has put extensive effort into estimating causal pecuniary and non-pecuniary effects of education (see, for example, Card, 1999; Stephens and Yang, 2013 and references in this work as well as the recent surveys on non-pecuniary effects of schooling by Lochner, 2011 and Oreopoulos and Salvanes, 2011). Most of our understanding about the importance of education is from estimating causal effects of an additional year of schooling. To achieve identification, scholars have used instrumental variable approaches based, for instance, on distance to institutions of education (Card, 1993; Altonji et al., 2005a; Freier and Storck, 2012), or changes in 
compulsory schooling laws (Angrist and Krueger, 1991; Harmon and Walker, 1995; Oreopoulos, 2006; Pischke and Wachter, 2008; Brunello et al., 2009).

A second related body of literature studies the effects of being admitted to university in general, or to a particular college, or obtaining a certain degree or class of degree. Hoekstra (2009) and Saavedra (2009), for example, use a fuzzy regression discontinuity design based on university admission rules and report sizable positive effects of graduating from particular colleges on labor market outcomes such as employment and earnings. Kane and Rouse (1995), Jacobson et al. (2005) and Jepsen et al. (2014) study economic returns of attending colleges in the United States. The most recent study by Jepsen et al. (2014) analyzes labor market returns to community college degrees, diplomas, and certificates based on administrative panel data from Kentucky. The authors find sizable positive returns, with associate's degrees and diplomas resulting in quarterly earnings returns of around $\$ 1,500$ for men and $\$ 2,000$ for women. Oyer and Schaefer $(2010,2012 a, b)$ find for the U.S. that lawyers who graduated from the highest ranked law schools work more often in prestigious law firms and earn considerably more than lawyers from lower ranked schools. The paper that is closest to our analysis is a study by Di Pietro (2010) for the United Kingdom. He finds that graduates just above or below several grade cut-offs - degree classes - do not differ significantly in their probability of being in employment or in continued education six months after graduation.

The present study contributes to this literature in several ways. First, it provides one of the first estimates on the labor market returns to graduating with honors among university students. While previous studies mainly identify the causal effect of human capital at the lower end of the education distribution, our analysis focuses on earnings returns at the upper end. Second, rich longitudinal data allows us to control for a comprehensive set of proxy variables for individuals' ability, intelligence, and social background, as we have information on graduates' high school grade point average, their university performances as well as on their mother's and father's highest general school degree and their parents' highest vocational qualification obtained. Third, our study is the first in the field that combines a difference-in-differences method with entropy balancing to estimate causal labor market returns to graduating from university.

Our analysis is based on data from the University Graduates Panel (Absolventenpanel) provided by the DZHW organization (German Centre for Research on Higher Education and Science Studies). In the data, we first observe individuals one year 
after receiving their initial university degree. At this point, we observe their treatment status and collect important pre-determined characteristics such as gender, age, high school grade, comprehensive information on parental background, and academic career choice during the period of studies. Five to six years after graduation, the same individuals are surveyed a second time. We use monthly gross earnings from this second wave as the outcome of interest.

Methodologically, we use a number of different strategies to identify the treatment effects. In the descriptive part of the paper, we use regression-control, matching techniques and entropy balancing. In our main specifications, we rely on a differencein-differences (DiD) research design and a DiD strategy combined with entropy balancing. In these specifications, we make use of the fact that students of other subjects also take state bar exams, but do not have an explicit honors degree. By comparing law graduates (with and without an honors degree) to students of medicine and pharmacy (students with a high or low grade point average), we isolate the particular effects of the honors degree. In the sensitivity analysis, we also compare law graduates to economics and education graduates to shed additional light on the generalizability of our estimates. Our empirical findings suggest strong effects of obtaining an honors degree on future labor earnings. We find that students of law who passed the state bar exam with an honors degree receive a sizable and significant earnings premium of about 14 percent. Thus, we provide new evidence on the returns to education at the upper end of the education distribution and complement the literature estimating treatment effects at the lower end of education levels. The results are robust to various sensitivity analyses. Importantly, using a novel econometric estimation method to assess potential biases from unobservables (Oster, 2014), the DiD estimates are found to be robust to omitted variable bias.

The paper is structured as follows: Section 2 lays out the institutional framework, Section 3 introduces the data, and Section 4 discusses the empirical models. The key findings and various robustness checks are presented in Section 5. The final section concludes.

\section{$2 \quad$ Background and Institutional Setting}

Law continues to rank among the most popular subjects for university studies in many industrialized countries, including Germany. In 2012, around 103,000 students 
(four percent of the student population) studied law in Germany. ${ }^{1}$ Unlike in most other fields of study, the examination for law graduates is not the responsibility of the universities, but instead it is organized by specific state law examination boards (Landesjustizprüfungsämter). While the education is state-specific, a law degree from any German state qualifies a student to practice law in the entire country.

Law students in Germany have to complete four stages to be able to practice law in all its varieties. First, students have to study law at a German university. On average, students attend university for ten semesters during which they study various fields of law. In order to successfully complete their studies at university, students take courses in civil, criminal, public, and procedural law, and one elective (Schwerpunktbereich), for instance, European and international law. Law students learn about the philosophical, historical, and social foundations of the law and techniques for applying the law in case studies.

After successfully completing their university education, students are entitled to register for the first state bar examination (Erstes Staatsexamen). ${ }^{2}$ The first bar exam consists of several written tests followed by an oral test and a presentation. The exact regulations for the examination vary slightly across states. For example, the number of written tests varies between four and nine, and some states use different weighting for the written and the oral parts of the exam for the final grade point average. The committee that conducts the oral examination knows the results from the written tests and is therefore in a position to ultimately decide on the final grade. ${ }^{3}$ The grading scale for the final grade point average varies between 0 and 18 points and the grading is as detailed as two decimal points. A student passes the exam with four or more points. Traditionally, the field of law formally distinguishes graduates with an honors degree if they pass the final grade of the first exam with nine points or more. The grading scheme is very selective at the top. In 2005, for example, about 15.8 percent

\footnotetext{
${ }^{1}$ See, for example, https://www.destatis.de/DE/ZahlenFakten/Indikatoren/LangeReihen/ Bildung/lrbil03.html.

${ }^{2}$ The first bar exam was reformed in 2003. Students who began their studies prior to 2003 and registered for the first bar exam no later than July 1, 2006, were tested according to the old examination regulations. This paper studies law graduates who graduated before the reform became effective.

${ }^{3}$ Generally, students are allowed to repeat the first bar exam once if they fail; those who pass the exam are not allowed to repeat it to obtain a better grade. Additionally, students who studied without interruption and registered for the exam before the end of the eighth and final semester are granted one extra free attempt (Freiversuch); those who fail the free attempt are allowed to repeat the exam as if they had not participated in the free attempt; those who pass the free attempt are allowed to repeat the exam once more to improve their grades. In our data, less than one percent of the graduates of the cohorts 1993 and 1997 indicated they had repeated the first bar exam after a free attempt. Unfortunately, we do not have this information for other cohorts.
} 
of all first bar examinees in law obtained an honors degree and only about three percent of all examinees scored a final grade above or equal to 11.5 points (Bundesamt für Justiz, 2006).

Conditional on passing the first exam, law candidates must complete a legal clerkship (Referendariat). This period typically lasts two to three years during which students acquire further knowledge in law. Here, the particular focus is on the code of procedure. The candidates practice law as interns at different institutions. Typically, students work at a minimum of four different legal institutions, for instance, practicing civil law at a district court, criminal law at a criminal court or with a prosecutor, working in the legal administration or in an administrative court, as well as doing an internship in an attorney's office or a law firm.

As the fourth (and final) step in becoming a fully qualified lawyer, candidates have to pass a second (state) bar exam (Zweites Staatsexamen). The second exam again comprises written and oral tests and a presentation on knowledge acquired during the period of legal clerkship. The grading scheme follows the same procedure as in the first exam. In the second exam, candidates can also earn an honors degree if they pass with an average above nine points.

Anecdotal evidence points to the paramount importance of receiving an honors degree for career prospects in the private and public sectors. For example, in recent articles in the weekly newspaper Der Spiegel, it is argued that the final exam grades are crucial throughout a lawyer's entire career and that the grades are considered to be the key criteria in the hiring process (SPIEGEL, 2011, 2013). In the private sector, the top ten private law firms in Germany seem to require an outstanding performance in the first and second state bar exam. ${ }^{4}$ Some firms explicitly state on their websites that they are seeking candidates with an honors degree. A Master of Law (LL.M.) and a doctorate degree are also mentioned as being advantageous.

In the public sector, the first and second bar exam are also of exceptional importance. Judges and prosecutors are employed and recruited by the ministries of justice and higher regional courts of the federal states. According to the employment regulations posted on the official websites of these institutions, hiring criteria include an honors degree in the first and/or second bar exam with slight differences across states. ${ }^{5}$ Furthermore, the final grade of the second bar exam is still a crucial factor in the decision

\footnotetext{
${ }^{4}$ For an overview of the largest private law firms in Germany, see, http://de.statista.com/ statistik/daten/studie/191422/umfrage/die-zehn-groessten-kanzleien-in-deutschlandnach-anzahl-der-anwaelte/.

${ }^{5}$ About two-thirds of the federal states require minimum standards with respect to the first and
} 
whether a practicing lawyer with three to five years of work experience is allowed to work as a notary.

\section{$3 \quad$ Data and Descriptive Statistics}

We use data from the University Graduates Panel (Absolventenpanel) from the DZHW organization (German Centre for Research on Higher Education and Science Studies) in Hanover. ${ }^{6}$ Studies that have also used DZHW data are, for example, Parey and Waldinger (2011) and Grave and Goerlitz (2012). While the data contains information on university graduates from all fields, we focus mainly on law graduates. In the difference-in-differences specifications, we also use data for graduates from medicine and pharmacy, who also obtain state-certified degrees (Staatsexamen) when graduating from university. However, there are no explicit honors degrees in these fields. In sensitivity analyses, we also use economics and education graduates as alternative comparison groups.

We make use of the initial survey waves from the years 1994, 1998, 2002, and 2006. The initial surveys were conducted around one year after students passed the first state bar exam. These surveys collect important information such as high school grade point average, location of high school (eastern or western Germany), completion of an apprenticeship before studying, duration of studies (in semesters), age at graduation, location of university (eastern or western Germany), and the highest general school degree, job qualifications and employment status of both parents. After four to five years, graduates are invited to participate in a follow-up survey (see Figure A-1 in the appendix for an illustration of our data structure). The follow-up surveys mainly collect labor market information. Overall, our main sample consists of around 800 law graduates and 1,400 medical and pharmacy graduates who successfully completed their university studies and state bar exams between 1993 and 2005.

Table 1 shows summary statistics, separately for the sample of law graduates and the sample of medical and pharmacy graduates. Column 1 in Table 1 shows that, five to

second bar exam. For example, Saxony, Saxony-Anhalt and Schleswig-Holstein explicitly require an honors degree in both exams. Other states only require one of the exams to be an honors degree while the other should have been passed with at least 8.0 points. About one-third of the federal states indicate that they also employ graduates without an honors degree in either of the exams, but state that they prefer graduates with an honors degree in both exams. Around two-thirds of the federal states apply rules which mainly concern the second bar exam. However, Bavaria and Rhineland-Palatinate are the only states which indicate that they only consider the grades obtained in the second bar exam in the hiring process.

${ }^{6}$ For detailed information about the data and the surveys, see http://www.dzhw.eu. 
six years after passing the first bar exam, law graduates have average gross earnings of around 3,660 euros per month (expressed in 2010 prices). ${ }^{7}$ Graduates in medicine and pharmacy earn 4,260 euros a month on average. The unconditional difference in the earnings between law graduates and graduates in medicine and pharmacy is statistically significant at the one percent level, as indicated by two-sample mean comparison tests in column 5 of Table 1.

The most important explanatory variable in our study is an indicator variable that takes the value one if a student of law obtained an honors degree, or medical and pharmacy students have a final grade in the top level of the grade distribution. To generate this variable, we make use of the self-reported grade point average in the first state bar exam which is reported in the initial survey waves (e.g. from survey years 1994, 1998, 2002, and 2006). ${ }^{8}$ Law students who report a final grade of nine or above are defined as having an honors degree. Column 1 in Table 1 shows that 30 percent of law students received an honors degree in their first state bar exam. Column 3 reports the average grades of the final exam for medical and pharmacy graduates. It should be noted that the scale of grading differs from that of law graduates. Medical and pharmacy students receive a final grade between 1.0 and 4.0, with a one indicating the highest, and a four indicating the lowest possible grade. On average, students from these fields leave university with a grade of 2.24. In order to distinguish between high- and lower-performing students among the medical and pharmacy graduates, we define those students who are in the top 23 percent of the grade distribution as high-performing students (equivalent to law graduates with an honors degree) and the others as lower-performing students (equivalent to law graduates without an honors degree). ${ }^{9}$ Results obtained using alternative thresholds are also presented in the robustness section below. High-performing students in medicine and pharmacy are alternatively defined as those whose final grade is among the top 18, 25, 27, 30, and 32 percent in the grade distribution. Figure 1 displays the distribution of the average grades in the first state bar exam, separately for law graduates and for medical and

\footnotetext{
${ }^{7}$ Graduates who report monthly gross earnings below 1,000 euros are dropped from the sample because measurement error is likely. This reduces the sample size by 69 observations (less than five percent). The estimates are similar when these individuals are included in the sample.

${ }^{8}$ For law graduates interviewed in 1994 and 1998, the grade variable takes integer values between 3 and 15, and in the waves 2001 and 2005, the grade average is shown to one decimal place.

${ }^{9}$ Because the grade distribution varies across graduation cohorts and because of the discreteness of the grading scales, defining exactly 30 percent of medical and pharmacy graduates as treated overall and in every cohort is infeasible. We therefore defined less than 30 percent as treated in every cohort resulting in a treated share of 23 percent overall. We decided to use this share in our main analysis to include only the most productive medical and pharmacy graduates in the treated group. This implies that our control group has a stricter definition of who obtained the honor status, which should make our difference-in-difference test stricter.
} 
pharmacy graduates. The figure shows that the majority of successful law candidates have an average grade between six and eight points, and only around ten percent score 12 or more points. Among medical and pharmacy students, around 25 percent graduate with a score higher than 2.0 , and only 10 percent graduate with a grade of 1.5 or better.

Figure 2 shows the distribution of the log of monthly gross earnings for lawyers with and without an honors degree (upper panel) and for medical and pharmacy graduates with and without a top grade in their state bar exam (lower panel). The upper panel shows considerable differences in the earnings distribution between lawyers with and without an honors degree in their state bar exam five to six years after graduating from university. The differences are particularly striking at the bottom and top percentiles. Among medical and pharmacy graduates, the differences in earnings between topperformers and lower-performing graduates are more pronounced in the center of the income distribution.

Table 1 also shows summary statistics for a comprehensive set of control variables, which are all obtained from the initial survey waves. These are gender, high school grade point average, location of high school (eastern or western Germany), completion of an apprenticeship before studying, duration of studies (in semesters), whether labor market aspects played a role in the choice in the field of study, age at graduation from university, location of university (eastern or western Germany), having a child at the time of graduation, parents' highest general school degree, highest job qualification obtained, and mother's and father's employment status at the time of the interview for the initial survey. The descriptive statistics on parental background show, for example, that most graduates have highly educated parents, with 49 (53) percent of all fathers of law (medical and pharmacy) graduates having obtained a university entrance qualification.

\section{Empirical Specifications}

A variety of different empirical strategies are used to estimate the effects of obtaining an honors degree on subsequent labor market outcomes. This section describes the empirical models in two parts. First, in the descriptive part, estimation methods that rely on the selection on observables assumption are discussed. Here, ordinary least square specifications (OLS), propensity score matching and entropy balancing estimators (PSMATCH and ENTROPY) are used, as well as fully interacted linear 
models (FILM). These methods are estimated using our sample of 828 lawyers. Second, approaches are introduced that aim to make use of quasi-experimental variation: a difference-in-differences specification (DiD) and a DiD research design combined with entropy balancing. For the DiD methods, the sample used consists of around 2,200 law, medical and pharmacy graduates.

\subsection{Selection on Observables Research Designs}

We begin our empirical analysis using a regression-control framework. The basic OLS specification is as follows:

$$
Y_{i}=\beta_{0}+\beta_{1} \text { Honor }_{i}+X_{i} \delta+\epsilon_{i}
$$

for $i=1,2 \ldots, 828$ lawyers. $Y_{i}$ indicates $\log$ earnings of individual $i$, Honor $_{i}$ is an indicator variable that takes the value one if the individual obtained an honors degree in law, and the vector $X_{i}$ includes a rich set of control variables.

The parameter of interest is $\beta_{1}$. To consistently estimate the causal effect of an honors degree, we require that $E\left(\epsilon_{i} \mid\right.$ Honor $\left._{i}, X_{i}\right)=0$. This leads us to the selection on observables assumption that the OLS estimate ultimately hinges on. Given the set of observable control variables in $X_{i}$, our treatment variable Honor $s_{i}$ must be independent of additional confounding factors that also affect labor market outcomes, but remain unobserved in equation (1).

Hence, whether the OLS produces reliable estimates depends on the quality and relevance of the control variables in $X_{i}$. There are a number of obvious concerns about the exogeneity assumption of obtaining an honors degree. The first is that individuals' ability is of crucial importance both for selection into treatment as well as for labor market outcomes. Similarly, it is very likely that students' motivation, intelligence, and persistence are key drivers for obtaining an honors degree, and also for performing well in the labor market. While it is almost impossible to control for all relevant factors, the DZHW data allows us to capture what we believe to be the most important background characteristics. Apart from gender and age, the data provides information on the high-school grade performance that can serve as a proxy for students' ability and motivation. Moreover, self-reported indicators on the student effort over the period of studies are available (particularly the duration of studies and the motivation for studying with regard to the labor market). Finally, we can also control for the educational background and employment status of both the mother and the father. The literature on intergenerational transmission of educational and 
labor market outcomes advises us to also control for parental characteristics (see, for example, Björklund et al., 2006).

In addition to a regression-control framework, we also estimate propensity score and entropy balancing models. While matching relies on the same selection on observables assumption as OLS, the assumptions on functional form are markedly different. In the matching regressions, we identify the average treatment effect on the treated (ATT) by linking a number of control observations to each treated observation. Under the assumption that selection into treatment depends only on the variables that we observe, our estimate of the effect of an honors degree is consistently identified by taking the difference between law graduates with an honors degree and the appropriately weighted control group (those without an honors degree):

$$
A T T=\frac{1}{N_{T}} \sum_{i=1}^{N_{T}}\left(Y_{T, i}-\sum_{j=1}^{N_{N T}} \omega(i, j) Y_{N T, j}\right)
$$

where, $N_{T}$ and $N_{N T}$ are the number of treated and non-treated observations, respectively. The function $\omega(i, j)$ assigns a weight to individual $j$ in the non-treated group depending on the identity of individual $i$ in the treatment group. In practice, this weighting function can take different forms. We use radius matching in which we link each treated observation to all observations in the control group with a propensity score within a 0.01 caliper. In robustness checks, we also test the results with alternative matching estimators. ${ }^{10}$

Apart from the propensity score matching, we also apply entropy balancing as a reweighting technique to ensure comparability of the treatment and the control group. Entropy balancing assigns a weight to each observation of the control group directly so that the moments of the control variables of the reweighted control group are equal to the moments of the treated group (Hainmueller and $\mathrm{Xu}, 2013$; Hainmueller, 2012). The weights are calculated so that a loss function using the directed Kullback (1959) entropy divergence as a distance metric is minimized under a set of pre-specified balance constraints imposed on the sample moments of the control variables. In the paper, the control variables' first three moments - namely the mean, variance and skewness - of the treatment and the control group are balanced. The main advantages of using entropy balancing rather than propensity matching techniques are an increase in balance quality, and the redundancy of potentially tedious balance checks since the covariate moments are automatically balanced by the algorithm (Hainmueller, 2012).

\footnotetext{
${ }^{10}$ To implement matching, we use the Stata program psmatch2 (Leuven and Sianesi, 2012).
} 
Fully interacted linear models are used to complement the OLS and matching analyses. Here, the treatment variable is interacted with all control variables to allow for maximal flexibility (also testing for heterogeneity in the treatment effect). If the treatment effect is driven only by one or several control variables, the FILM would pick that up. Note that, while the basic OLS does not allow for any heterogeneity in the treatment effect, the matching implicitly allows for complete flexibility, as each treated observation is assigned a set of control observations. Consequently, the FILM provides an in-between solution between OLS and matching. The specification for the FILM reads as follows:

$$
Y_{i}=\beta_{0}+\beta_{1} \text { Honors }_{i}+X_{i} \delta_{0}+\left(X_{i} \cdot \text { Honor }_{i}\right) \delta_{1}+\vartheta_{i}
$$

where the addition to equation (1) is the term $X_{i}$. Honor $s_{i}$, which describes the interaction effects of all control variables with the treatment dummy. ${ }^{11}$

\subsection{Difference-in-Differences Research Design}

In this section, we describe the difference-in-differences (DiD) approaches. These are our main specifications, as they arguably rely on weaker identifying assumptions than the models based on the selection on observables assumption.

In the $\mathrm{DiD}$ research design, we make use of the fact that the DZHW data has information not only on law graduates, but also on university graduates from other fields. Graduates in medicine and pharmacy also obtain a formal degree from the state authorities (Staatsexamen), but there is no specific honors degree in medicine and pharmacy that can be obtained when graduating with a good or very good grade. Since medical and pharmacy students also have to pass a state bar exam, they are an appropriate comparison group. In the robustness section below, we also report the results when using economics graduates and teachers as alternative comparison groups.

The main idea of the DiD research design in our setting is to compare labor earnings of law students to students of medicine and pharmacy across the grade distribution in the first state bar exam. In particular, we compare labor market outcomes of four different groups: high- and lower-performing students from law, and medicine and pharmacy, respectively. As about 30 percent of all students in law included in the data obtain an honors degree, we also code the best students in the other two fields

\footnotetext{
${ }^{11}$ For a FILM application see for instance Battistin et al. (2012).
} 
into an artificial honors degree group (although they do not formally obtain a degree with honors). The empirical model is specified as follows:

$$
Y_{i}=\gamma_{0}+\gamma_{1} \text { Honor }_{i}+\gamma_{2} \text { Law }_{i}+\gamma_{3}\left(\text { Law }_{i} \cdot \text { Honor }_{i}\right)+X_{i} \delta+\varphi_{i},
$$

for $i=1,2 \ldots, 2199$ law, medical and pharmacy graduates. The parameter of interest is $\gamma_{3}$, measuring the additional contribution to the outcome variable that can be attributed to the interaction between an honors degree and the field of law. The main assumption of the DiD research design is the common trend assumption. In the absence of a formal honors degree in law, earnings between high-performing and lowerperforming students in law, and in medicine and pharmacy should evolve equally. We investigate the common trend assumption in section 5.3.

We also combine the differences-in-differences estimator with entropy balancing. Combining both methods has several advantages over using one estimation method only. The basic idea of combining difference-in-differences with matching is to reduce bias due to grade-invariant unobservables, and bias due to different distributions of covariates in the treatment and control groups (Heckman et al., 1997; Blundell et al., 2004; Abadie, 2005). In the context of this paper, we first use entropy balancing within groups so that law graduates with an honors degree are matched to law graduates without an honors degree, and medical and pharmacy graduates at the top of the grade distribution are matched to medical and pharmacy graduates with lower grades. The entropy balancing part of the estimator reduces bias due to differences in observables between the treatment and control groups. We then use the difference-indifferences part of the estimator to reduce bias due to unobservables that accompany the increase in the skill distribution, but should remain constant between the treatment and control groups.

\section{Results}

The results are presented in four steps. First, the descriptive evidence from the selection on observables models are discussed. Next, the results from the differencein-differences specifications with and without entropy balancing are presented. In subsection 5.3, we turn to the robustness exercises. Finally, some limitations and potential concerns are addressed in Section 5.4. 


\subsection{Selection on Observables Models}

Table 2 shows the results from five different selection on observable models for the log of monthly gross earnings as outcome. The first two columns in Table 2 present OLS estimates with different sets of covariates. Column 1 presents the results of a simple linear regression with an indicator variable for having an honors degree as the only explanatory variable. The OLS regression in column 2 additionally controls for a rich set of explanatory variables such as individual's age, gender, high school grade, duration of studies, motivation of study choice with respect to labor market aspects, cohort indicators and parental background including highest educational qualification and economic status at the time of graduation. ${ }^{12}$ Column 3 in Table 2 contains the results obtained from the fully interacted linear models, and columns 4 and 5 report the estimates from propensity score and entropy balancing models, respectively. Each estimated coefficient presents the results of a separate regression, with robust standard errors in parentheses. The estimates of graduating with honors are notably positive and significant in all models and specifications. In the simple OLS regression in column 1, the estimate suggests positive earnings returns to graduating with honors of 24 percent (exp(0.218)-1) ${ }^{13}$ However, when controlling for additional explanatory variables, the estimates drop considerably. Nevertheless, they remain significantly positive at about 13 percent. These results are notable because the magnitude of the effect drops by almost 50 percent when controlling for important background variables, such as the average high school grade and parents' highest educational degree, which are likely to be good proxies for unobserved factors, such as motivation, ability, and intelligence. Hence, the simple OLS estimates are likely to be biased upwards. The magnitude of the earnings returns is confirmed by the FILM, PSMATCH and ENTROPY estimates. These models also suggest positive and statistically significant earnings returns of around 14 to 15 percent. ${ }^{14}$

\footnotetext{
${ }^{12}$ See notes to Table 2 for the full list of explanatory variables. Estimated coefficients for all explanatory variables are reported in Table A-1 in the appendix.

${ }^{13}$ Note that, throughout the present article, the estimated coefficients are interpreted in terms of percentage changes in the log-level models using the formulas $\left(\exp \left(\hat{\beta}_{1}\right)-1\right)$ and $\left(\exp \left(\hat{\gamma}_{3}\right)-1\right)$.

${ }^{14}$ Figure A-2 shows that common support in the radius caliper matching model (Table 2, column 4) is substantial. Table A-2 highlights that balancing is almost perfect in the entropy balancing model (Table 2, column 5). Table A-4 shows that the results are robust using various matching techniques including radius matching with smaller and larger calipers (columns 1 and 2), nearest neighbor and kernel matching (columns 3 and 4), Mahalanobis distance matching (column 5) and entropy balancing models conditioning on the means and variances (column 6) and the means only (column 7). For a detailed overview of the various propensity score matching methods, see, for example, Caliendo and Kopeinig (2008).
} 


\subsection{Difference-in-Differences Models}

Table 3 shows the results of our difference-in-differences specifications. Columns 1 and 2 present the estimates from simple difference-in-differences regressions, and columns 3 and 4 show the results from difference-in-differences models combined with entropy balancing. ${ }^{15}$ We report the results from two different specifications for each estimation method. In the first specification, we do not control for additional explanatory variables other than Honor $s_{i}$, Law $_{i}$ and the interaction of these two variables Honors $_{i} * L a w_{i}$. In the second specification, we add a rich set of control variables and cohort-fixed effects. ${ }^{16}$ When interpreting the results, we focus our attention on the estimate of the parameter $\gamma_{3}$ from equation (4), i.e., the estimated coefficient on the interaction term of graduating in law with an honors degree.

We again find sizable and significant positive effects of graduating with an honors degree. The DiD estimate in column 2 suggests that graduating with an honors degree increases earnings by around 19 percent $(\exp (0.174)-1)$. The results from our preferred specification - the DiD research design combined with entropy balancingin column 4 also point to positive earnings effects in the order of 14 percent. Note that the magnitude of this effect is very similar to the estimates in Table 2, columns 2 to 5 . In fact, the DiD combined with entropy balancing estimate is not significantly different from any of the point estimates in columns 2 to 5 in Table 2. As a benchmark for the magnitude of the effect, note that Oreopoulos (2006), for example, reports positive returns to earnings from compulsory schooling in the U.S., U.K. and Canada of between 10 and 14 percent. Hence, the economic returns to an honors degree are comparable to roughly one more year of education.

\subsection{Robustness and Validity}

In this section, we evaluate the robustness and validity of our results. First, we assess the common trend assumption graphically and conduct robustness checks with respect to the pretreatment trend. Second, we examine whether the DiD findings are likely to be driven by unobserved variables. Third, several robustness specifications for the DiD research design combined with entropy balancing are presented. Finally, the potential problem of selected attrition is examined.

\footnotetext{
${ }^{15}$ Tables A-2 and A-3 report the balancing results of the initial entropy balancing procedures for law graduates, and for medical and pharmacy graduates respectively.

${ }^{16}$ In the difference-in-differences combined with entropy balancing model, the first specification implies that the control variables and cohort-fixed effects are not used in the second stage of the estimation (DiD). However, all control variables are used in the initial entropy balancing procedures.
} 
Common Trend Assumption. The common trend assumption is crucial for the validity of our main results. In this application, the common trend assumption entails that the log of monthly gross earnings should evolve equally for graduates in law, and graduates in medicine and pharmacy in the absence of a formal honors degree in law. In Figure 3, we investigate whether this assumption is likely to hold. The main problem of analyzing the common trend in our setting are the different grading scales in law on the one hand, and medicine and pharmacy on the other hand - a common grading scale is not available. We therefore graphically display the average value of the log earnings per score (grade) percentile for law (medical and pharmacy) graduates. ${ }^{17}$ The figure displays a common trend in the development of demeaned log earnings to the left of the honors threshold (displayed by the vertical black dashed line) at most parts of the distribution. Overall, the common trend appears to be satisfied reasonably well.

A cause for concern, however, is the decline in log earnings in the 41-50 percentile category. As a robustness check, we therefore drop observations-law as well as medical and pharmacy graduates - of this category from the estimation sample (see Table A5). The advantage of excluding these individuals from the sample is that the common trend assumption is more likely to hold. The disadvantage is the reduction in sample size and the risk of selection bias. The reduction in sample size can be substantial since it is impossible to drop exactly 10 percent of individuals due to the discreteness of the grading scales and the associated bunching at the distinct scores and grades. We therefore implement two approaches to address this trade-off and the sample size problem. First, in column 2 of Table A-5, we randomly draw and drop about 50 percent of individuals of grade categories which overlap with the 41-50 percentile category for each field of study separately to assign this group less weight in the estimationthis excludes about 10 percent of observations. ${ }^{18}$ Second, in column 3 , we exclude all individuals of score and grade categories which overlap with the 41-50 percentile category - this excludes about 23 percent of observations. The DiD estimates of the interaction term in columns 2 and 3 are very similar to the main result in column 1 and remain statistically significant. The DiD and entropy balancing estimates of the

\footnotetext{
${ }^{17}$ Because of the grouped and rounded nature of the scores (grades) and bunching (e.g., many medicine students graduate with a 2.0 ), it is impossible to precisely distinguish between percentiles. We therefore calculate the average log earnings per score (grade) first. Second, based on the relative frequencies of the scores (grades), we calculate weights based on the overlap of the score (grade) categories with the performance percentile categories. Third, using these weights and the log earnings averages per score (grade) we calculate average log earnings for each performance percentile.

${ }^{18}$ The grade categories which comprise the 41-50 percentile are the 2.0 and 2.1 grade categories for medical and pharmacy graduates and the 7 points category for law graduates.
} 
interaction term decline and become statistically insignificant. Note, however, that the sensitivity check in column 3 might be too restrictive because about 23 percent of individuals are omitted from the sample. Overall, we argue that the common trend assumption is likely to hold.

Omitted Variable Bias. Finally, we study the robustness of our DiD findings to omitted variable bias. Building on the work by Altonji et al. (2005b) and Altonji et al. (2008), Oster (2014) developed a new estimation method examining how robust estimates are to omitted variable bias by studying coefficient movements and movements in R-squared values when including additional explanatory variables. Applied to our basic DiD specifications (Table 3, column 2), Oster (2014) suggests calculating an identified set for the treatment effect together with the following bias-adjusted coefficient:

$$
\gamma_{3}^{\star \prime}=\tilde{\gamma}_{3}-\tilde{\delta} \frac{\left(\dot{\gamma}_{3}-\tilde{\gamma}_{3}\right)\left(R_{\max }-\tilde{R}\right)}{(\tilde{R}-\dot{R})},
$$

for $\tilde{\delta}=1 .{ }^{19}$ The bias-adjusted coefficient is a function of estimated parameters $\left(\dot{\gamma}_{3}, \tilde{\gamma}_{3}, \dot{R}, \tilde{R}\right)$ and chosen values for $\tilde{\delta}$ and $R_{\max }$. In the present study, the estimated coefficient $\dot{\gamma}_{3}$ and the R-squared $\dot{R}$ come from a simple DiD regression of equation (4) without additional explanatory variables (i.e., excluding the vector $X_{i}$ ), and $\tilde{\gamma}_{3}$ and $\tilde{R}$ stem from estimating equation (4) with all explanatory variables. $\tilde{\delta}$, the so-called coefficient of proportionality, captures the explanatory power of unobserved variables as a proportion of the explanatory power of observed variables. $R_{\max }$ denotes the $R^{2}$ of a hypothetical OLS regression if one could control for all relevant (observed and unobserved) variables.

To identify $\gamma_{3}^{\star \prime}$, assumptions for $\tilde{\delta}$ and $R_{\max }$ are required. According to Oster (2014), $\tilde{\delta} \in[0,1]$ is a useful bound. We assume that the influence of unobservables on the outcome variable is of similar magnitude as the impact of observable variables (i.e., $\tilde{\delta}=1$ ). We argue that this is a rather strict assumption, given that our full-model controls for important pre-determined explanatory variables, such as individuals' high school grade, their labor market orientation and parents' highest education. Further, Oster (2014) argues that $R_{\max }=\min \{2.2 \tilde{R}, 1\}$ is a useful bound. This yields the identified set $\left[\tilde{\gamma}_{3}, \gamma_{3}^{\star \prime}(\min \{2.2 \tilde{R}, 1\}, 1)\right]$ for our treatment effect of graduating with honors. In case the identified set excludes zero, the estimates from the full model (equation (4)) can be interpreted as being robust to omitted variable bias.

\footnotetext{
${ }^{19}$ For the estimation of $\gamma_{3}^{\star \prime}$ with values for $\tilde{\delta} \neq 1$ see Oster (2014).
} 
Table A-6 presents the results. The identified set for the treatment graduating with an honors degree on earnings is [0.125, 0.174]. Hence, the identified set excludes zero, and an omitted variable bias problem is therefore unlikely. Further, Oster (2014) also advises studying whether the bounds of the identified set are within the confidence interval of $\tilde{\gamma}_{3}$ to assess whether the magnitude of the effect is robust. This is also the case. Overall, the estimates in Table A-6 suggest that the positive earnings returns to graduating with an honors degree are very unlikely to be driven by omitted variables.

\section{Different Threshold Definitions and Omitting the Best Law Graduates.}

So far, we compared the labor earnings of honors degree students in law to students of law without an honors degree, relative to high-performing and lower-performing students in medicine and pharmacy. We assigned an honors degree to 23 percent of the best medicine and pharmacy students. However, medical and pharmacy graduates might experience sharp earnings increases at different points of the grade distribution which might not be adequately captured by the initial treatment definition in the control group. Table A-7 reports whether the results change when alternative thresholds are used, i.e., defining the best 18, 25, 27, 30, and 32 percent of medical and pharmacy students as high-performing graduates. Overall, the results lead to similar conclusions to those in Table 3. In particular, the estimates remain very stable when artificially defining more and more graduates as high-performing students in the control group. Second, the most productive law graduates with the highest scores in the first bar exam might drive the honors degree effect. In Table A-8, the best graduates in law are omitted from the sample. In column 4 , for instance, law graduates with a score of 13 points and above are excluded from the sample and law graduates with a score of 12 points or less are included in the sample. The estimates of the interaction term of the DiD and the DiD and entropy balancing specifications remain stable and statistically significant. Thus, the earnings premium estimate of an honors degree is not driven by law graduates at the very top of the score distribution.

Alternative Comparison Groups. In a further test of the DiD combined with entropy balancing approach, we compare labor market earnings of lawyers to those of economists and school teachers. Despite the fact that teachers in Germany generally have a very flat wage-skill profile, we use them as a comparison group in the robustness exercise because they also graduate with a state degree. In contrast, economists do not graduate with a state degree, but experience a wage-skill profile that is quite similar to those of lawyers. Further, a comparison with economics graduates is interesting because both economists and lawyers are likely to have careers in management and leadership positions. The estimates in Table A-9 indicate that our general findings do 
not change. Comparing law graduates to teachers or economists - instead of students of medicine and pharmacy — gives estimates with the same sign and similar magnitude as in the main specification.

Sample Attrition. Finally, we investigate possible biases due to selected sample attrition. Table A-10 shows the number of graduates participating in the two survey waves, separately for field of study and academic performance. The table documents that there is substantial attrition with only 49 (42) percent of law (medical and pharmacy) graduates participating in the second wave. Further, the unconditional means show a higher attrition rate among those without an honors degree or those who are low-performers, compared to high-performing graduates. To test whether differences in attrition rates between treatment and comparison group might bias our estimates, Table A-11 shows results from linear probability regressions and marginal effects from probit models on graduates' likelihood of participating in the second wave. Columns 1 and 2 in Table A-11 report whether law students with an honors degree are more likely to remain in the panel than those without an honors degree, and columns 3 and 4 report potential differences in panel attrition among medical and pharmacy students according to their performance in their studies. Finally, the last column in the table shows estimates from a DiD regression for law and medical and pharmacy graduates on the likelihood of participating in the second panel wave. None of the estimates in Table A-11 suggest significant differences in the attrition rate between treatment and comparison groups. Hence, it is very unlikely that the estimates are biased due to selected attrition.

\subsection{Discussion}

The results point towards sizable and significant effects of obtaining an honors degree on subsequent labor market earnings. We report estimates from the selection-onobservables models as well as from our quasi-experimental approaches in the order of 13-15 percent.

Two issues with the reported results warrant further discussion. First, we should again stress that we observe earnings for the law students (only) five to six years after they passed the first state bar exam. As law students spend two to three years in legal clerkship and often pursue a Ph.D. degree after the first bar exam, this implies that many are only at the beginning of their labor market career. Ideally, we would like to observe the individuals also later in life in order to examine long-term labor market effects of graduating with an honors degree. 
Second, we need to critically review the fact that we only use the first state bar exam as the treatment variable. Law students are also required to take a second state bar exam (which we have no information on in the data), in which they can again obtain an honors degree. Naturally, we would assume that graduates with honors degrees in both exams fare best in the labor market, compared to those without any or only one honors degree. Significantly, this restriction only limits the scope of our analysis, but is not a threat to the validity of our results. Even if we had data on the second exam, a joint analysis of both exams would not be straightforward, as the outcome of the second bar exam is very likely to be linked to that of the first. Hence, the second state bar exam might be considered as an outcome of the first state bar exam.

\section{Conclusions}

This paper presents evidence on the labor market returns to graduating with an honors degree. We exploit rich longitudinal data from the University Graduates Panel in Germany, which interviews students one and five to six years after graduating from university. The study examines the importance of honors degrees for future labor market success in the context of German law students who pass a state bar exam. Graduates in medicine and pharmacy, who constitute the comparison group, also obtain a formal degree from the state authorities (Staatsexamen). However, for these fields of study, there is no specific honors degree that can be obtained when graduating with an outstanding performance.

In the preferred specifications, we estimate the effects of an honors degree by applying a difference-in-differences estimation strategy combined with entropy balancing. By combining both methods, we argue that it is very likely that our findings are not driven by unobserved ability, family background, or different trends between treatment and comparison groups. The estimates suggest that graduating with an honors degree has substantial effects on individuals' labor market earnings. We find that students with an honors degree have around 14 percent higher earnings. The result is robust to various sensitivity analyses, such as different comparison groups (e.g., economics and education graduates), alternative definitions of graduating with an excellent grade among the comparison groups (e.g., being in the top 18 to 32 percent of the grade distribution), omitting the very best law graduates, as well as potential selected attrition. Importantly, the DiD estimates are unlikely to be driven by omitted variable bias (Oster, 2014).

The present findings complement the large body of literature on the returns to school- 
ing exploiting changes in compulsory schooling laws over time and across regions as exogenous variation. These studies mainly identify local average treatment effects at the lower end, whereas the present study estimates the returns at the upper end of the education distribution. Thus, we contribute to and complement the relatively small body of literature on economic returns to certificates and college degrees (Kane and Rouse, 1995; Jacobson et al., 2005; Jepsen et al., 2014). Overall, this is one of the first studies documenting that graduating from university with an outstanding performance has considerable causal effects on labor market earnings. 


\section{References}

Abadie, A. (2005): "Semiparametric Difference-in-Differences Estimators," Review of Economic Studies, 72, 1-19.

Altonji, J., T. Elder, And C. TABer (2005a): "An Evaluation of Instrumental Variable Strategies for Estimating the Effects of Catholic Schooling," Journal of Human Resources, 40, 791-821.

(2005b): "Selection on Observed and Unobserved Variables: Assessing the Effectiveness of Catholic Schools," Journal of Political Economy, 113, 151-184.

(2008): "Using Selection on Observed Variables to Assess Bias from Unobservables When Evaluating Swan-Ganz Catheterization," The American Economic Review, 98, 345-350.

Angrist, J. D. And A. B. Krueger (1991): "Does Compulsory School Attendance Affect Schooling and Earnings?" Quarterly Journal of Economics, 106, 979-1014.

Battistin, E., M. De Nadai, And B. Sianesi (2012): "Misreported Schooling, Multiple Measures and Returns to Educational Qualifications," IZA Discussion Paper 6337, IZA, Bonn.

Björklund, A., M. Lindahl, And E. Plug (2006): "The Origins of Intergenerational Associations: Lessons from Swedish Adoption Data," Quarterly Journal of Economics, 121, 999-1028.

Blundell, R., L. Dearden, A. Goodman, and H. Reed (2000): "The Returns to Higher Education in Britain: Evidence From a British Cohort," The Economic Journal, 110, 82-99.

Blundell, R., C. Meghir, M. C. Dias, And J. V. Reenen (2004): "Evaluating the Employment Impact of a Mandatory Job Search Program," Journal of the European Economic Association, 2, 569-606.

BRIEDIS, K. (2007): "Übergänge und Erfahrungen nach dem Hochschulabschluss: Ergebnisse der HIS-Absolventenbefragung des Jahrgangs 2005," Dokumentation HIS, Hannover.

Brunello, G., M. Fort, And G. Weber (2009): "Changes in Compulsory Schooling, Education and the Distribution of Wages in Europe," Economic Journal, 119, $516-539$. 
Bundesamt FÜR Justiz (2006): "Ausbildungsstatistik 2006," https://www . bundesjustizamt.de/justizstatistik, accessed: 2013-12-18.

Caliendo, M. And S. Kopeinig (2008): "Some Practical Guidance for the Implementation of Propensity Score Matching," Journal of Economic Surveys, 22, $31-72$.

CARD, D. (1993): "Using Geographic Variation in College Proximity to Estimate the Return to Schooling," Working Paper 4483, National Bureau of Economic Research. (1999): "The Causal Effect of Education on Earnings," in Handbook of Labor Economics, ed. by Orley C. Ashenfelter and David Card, Elsevier, vol. 3, Part A, 1801-1863.

Di Pietro, G. (2010): "The Impact of Degree Class on the First Destinations of Graduates: A Regression Discontinuity Approach," IZA Discussion Paper 4836, IZA, Bonn.

Freier, R. And J. Storck (2012): "The Treatment Effect of Attending a HighQuality School and the Influence of Unobservables," SOEPpapers on Multidisciplinary Panel Data Research 530, DIW Berlin, The German Socio-Economic Panel (SOEP).

Goldin, C. D. And L. F. KATz (2010): The Race between Education and Technology, Cambridge: Harvard University Press.

Grave, B. S. And K. Goerlitz (2012): "Wage Differentials by Field of Study The Case of German University Graduates," Education Economics, 20, 284-302.

Hainmueller, J. (2012): "Entropy Balancing for Causal Effects: A Multivariate Reweighting Method to Produce Balanced Samples in Observational Studies," Political Analysis, 20, 25-46.

Hainmueller, J. AND Y. XU (2013): "ebalance: A Stata Package for Entropy Balancing," Journal of Statistical Software, 54, 1-18.

Harmon, C. And I. Walker (1995): "Estimates of the Economic Return to Schooling for the United Kingdom," American Economic Review, 85, 1278-1286.

Heckman, J. J., H. Ichimura, And P. E. Todd (1997): "Matching As An Econometric Evaluation Estimator: Evidence from Evaluating a Job Training Programme," Review of Economic Studies, 64, 605-654. 
Hoekstra, M. (2009): "The Effect of Attending the Flagship State University on Earnings: A Discontinuity-Based Approach," Review of Economics and Statistics, $91,717-724$.

Jacobson, L., R. LaLonde, and D. G. Sullivan (2005): "Estimating the Returns to Community College Schooling for Displaced Workers," Journal of Econometrics, 125, 271-304.

Jepsen, C., K. Troske, and P. Coomes (2014): "The Labor-Market Returns to Community College Degrees, Diplomas, and Certificates," Journal of Labor Economics, 32, 95-121.

Kane, T. J. and C. E. Rouse (1995): "Labor-Market Returns to Two- and FourYear College," American Economic Review, 85, 600-614.

KullbaCK, S. (1959): Information theory and statistics, Wiley publications in statistics, New York, NY: Wiley [u.a.].

Leuven, E. And B. Sianesi (2012): "PSMATCH2: Stata Module to Perform Full Mahalanobis and Propensity Score Matching, Common Support Graphing, and Covariate Imbalance Testing," Software, http://ideas.repec.org/c/boc/bocode/ s432001.html, accessed: 2013-12-18.

Lochner, L. (2011): "Nonproduction Benefits of Education: Crime, Health, and Good Citizenship," in Handbook of the Economics of Education, ed. by S. M. Eric A. Hanushek and L. Woessmann, Elsevier, vol. Volume 4, 183-282.

OECD (2013): Education at a Glance 2013: OECD Indicators, OECD Publishing.

Oreopoulos, P. (2006): "Estimating Average and Local Average Treatment Effects of Education When Compulsory Schooling Laws Really Matter," American Economic Review, 96, 152-175.

Oreopoulos, P. And K. G. Salvanes (2011): "Priceless: The Nonpecuniary Benefits of Schooling," Journal of Economic Perspectives, 25, 159-184.

Oster, E. (2014): "Unobservable Selection and Coeffcient Stability: Theory and Evidence," Working Paper.

Oyer, P. And S. Schaefer (2010): "American BigLaw Lawyers and the Schools that Produce Them: A Profile and Rankings," Working Paper. 
(2012a): "Firm/Employee Matching: An Industry Study of American Lawyers," NBER Working Paper 18620.

(2012b): "Welcome to the Club: The Returns to An Elite Degree for American Lawyers," Working Paper.

Parey, M. And F. Waldinger (2011): "Studying Abroad and the Effect on International Labour Market Mobility: Evidence from the Introduction of ERASMUS," Economic Journal, 121, 194-222.

Pischke, J.-S. And T. V. Wachter (2008): "Zero Returns to Compulsory Schooling in Germany: Evidence and Interpretation," Review of Economics and Statistics, 90, 592-598.

SAaVEDRA, J. E. (2009): "The Learning and Early Labor Market Effects of College Quality: A Regression Discontinuity Analysis," Working Paper.

SPIEGEL (2011): "Jura-Absolventen: Sklaven der Noten," http://www . spiegel.de/karriere/berufsstart/jura-absolventen-sklaven-der-notena-753598.html, accessed: 2013-12-18.

(2013): "Berufsstart junger Juristen: Prädikat besonders wertvoll," http://www . spiegel. de/karriere/berufsstart/chancen-junger-juristenberufsstart-ohne-praedikatsexamen-a-913430.html, accessed: 2013-12-18.

Stephens, Melvin, J. And D.-Y. Yang (2013): "Compulsory Education and the Benefits of Schooling," American Economic Review, forthcoming. 
Figure 1: Histogram of average grade points in the first bar exam of law graduates and medical and pharmacy graduates
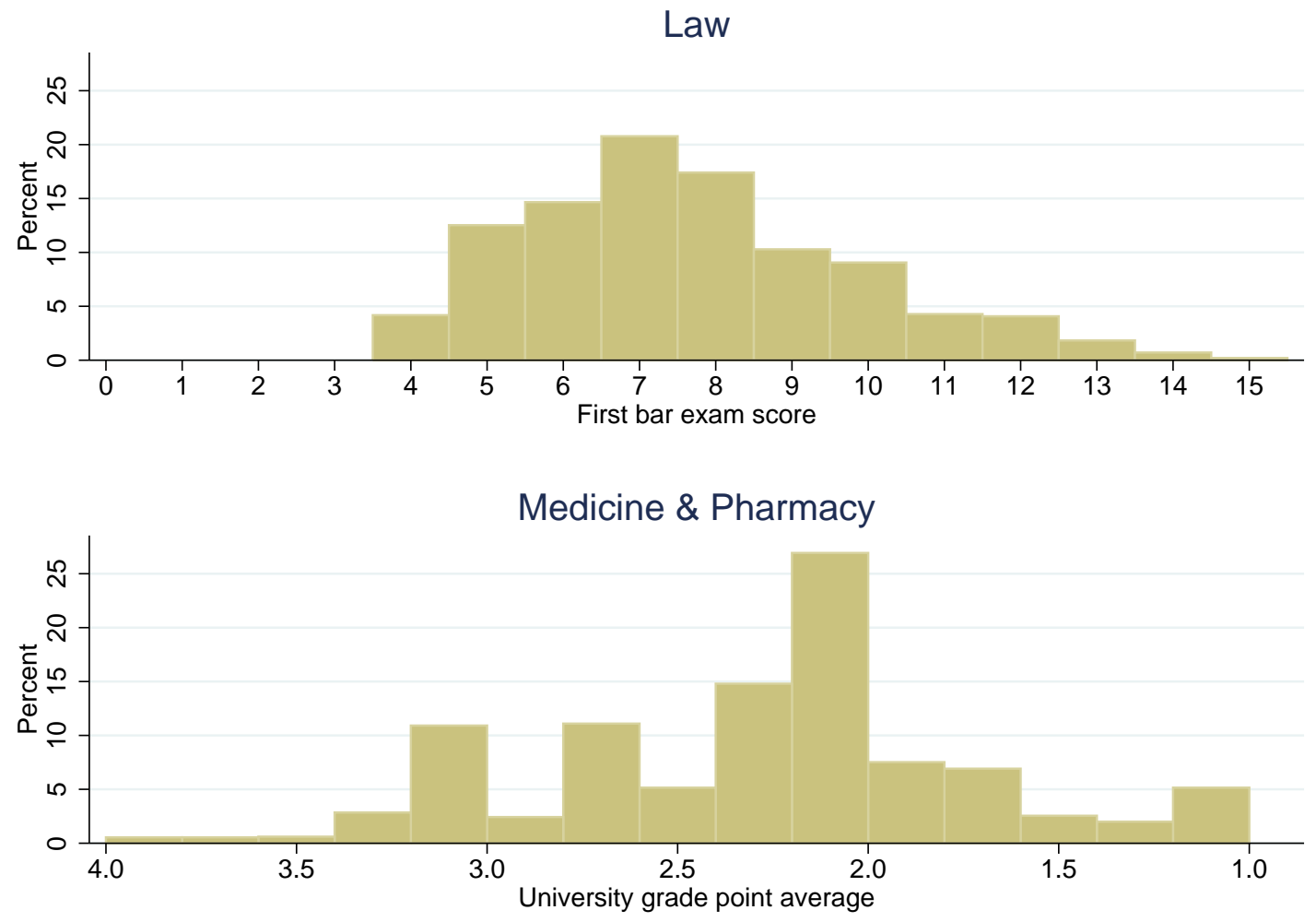

Notes: The upper (lower) panel displays the distribution of the average score (grade) of the first state bar exam of law (medicine and pharmacy) for students from the cohorts 1993, 1997, 2001 and 2005. The grading scale for lawyers is between 0-18 points. More points indicate a better performance. The grading scale for medical and pharmacy graduates is between 4.0 and 1.0 - the lower the grade, the better the performance. 
Figure 2: Kernel density of the log of monthly gross earnings of law graduates and medical and pharmacy graduates, by study performance
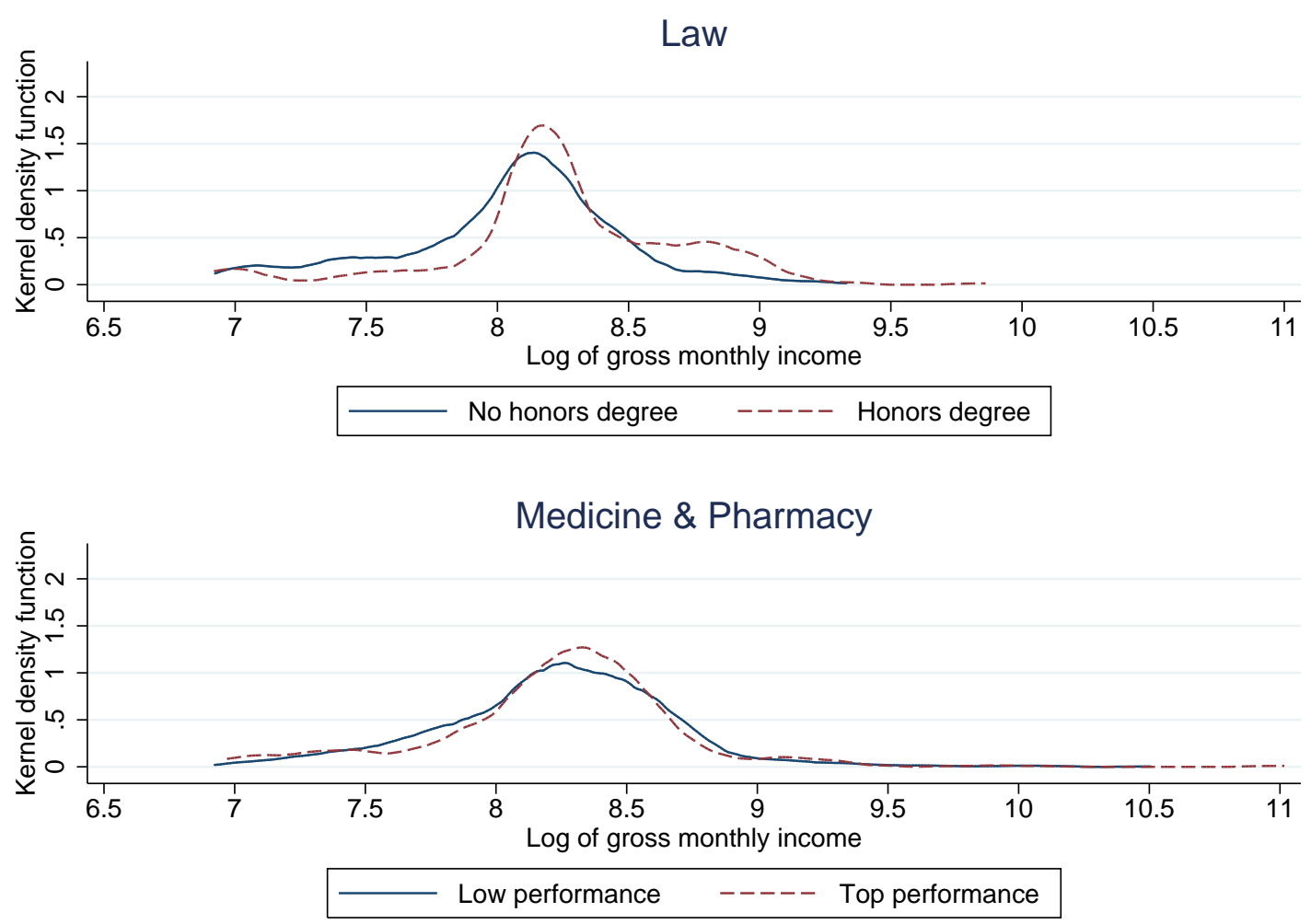

Notes: The upper (lower) panel in the figure shows kernel density functions of the log of monthly gross earnings separately for law graduates with an honors degree (medical and pharmacy graduates with a top study performance, i.e. among the best 23 percent) (dashed line) and law graduates without an honors degree (medical and pharmacy graduates without a top study performance) (solid line) using an Epanechnikov kernel. 
Figure 3: Difference-in-differences - common trend

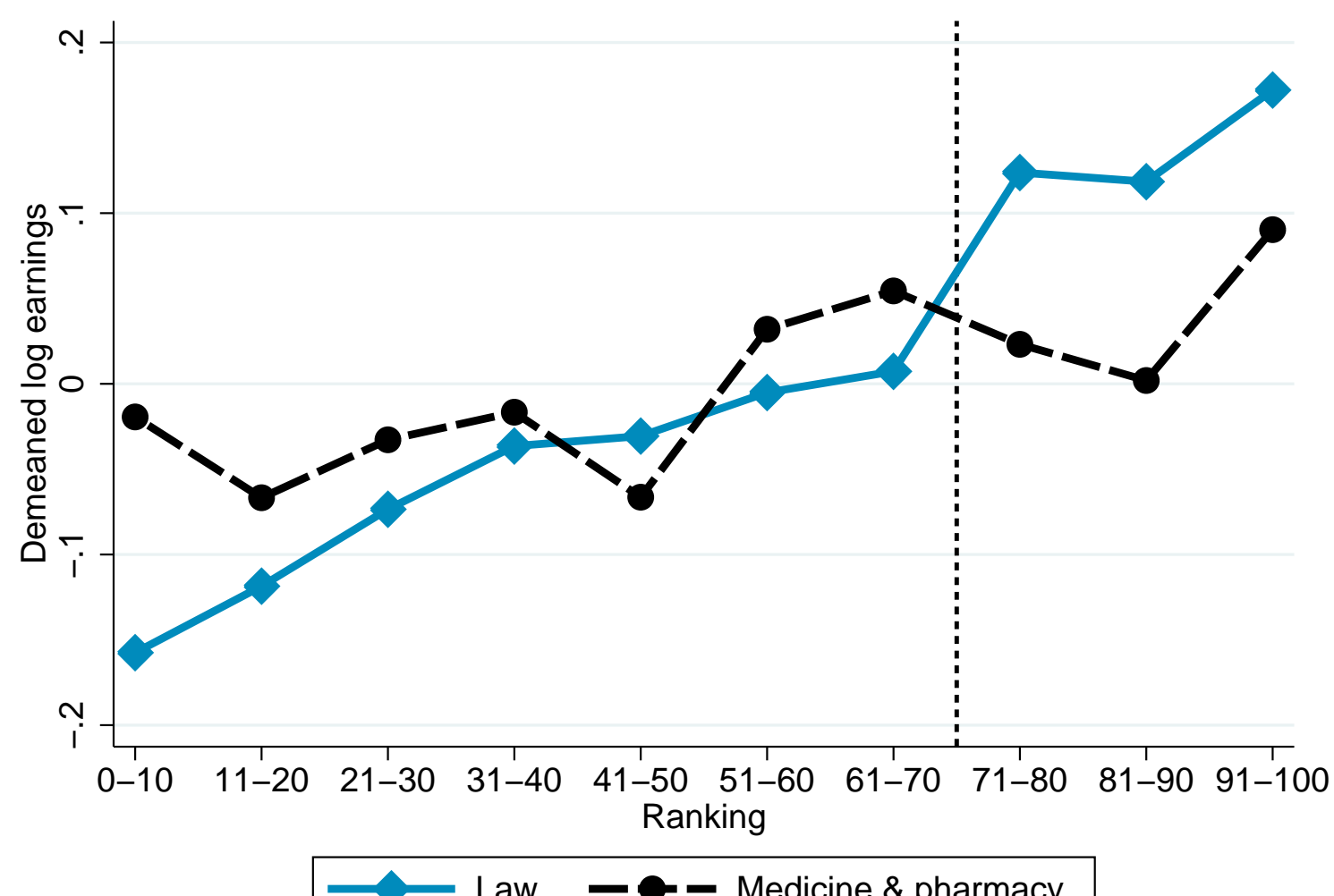

Notes: The figure shows the average value of the log of monthly gross earnings for each performance percentile for law graduates (blue solid line), and medical and pharmacy graduates (black dashed line). The log earnings are demeaned by the subject's overall mean. The category " $91-100 "$ comprises the best ten percent of graduates. The vertical black dashed line indicates the honors degree threshold; 30 percent of law graduates received an honors degree in the sample. 
Table 1: Descriptive statistics

\begin{tabular}{|c|c|c|c|c|c|}
\hline & \multicolumn{2}{|c|}{ Law } & \multicolumn{2}{|c|}{ Medicine \& pharmacy } & \multirow[b]{2}{*}{ Difference } \\
\hline & Mean & $\mathrm{Sd}$ & Mean & $\mathrm{Sd}$ & \\
\hline & $(1)$ & $(2)$ & $(3)$ & $(4)$ & $(5)$ \\
\hline \multicolumn{6}{|l|}{ Outcomes } \\
\hline Monthly gross earnings ${ }^{a}$ & 3663.72 & 1698.83 & 4257.00 & 2779.50 & $-593.279^{* * *}$ \\
\hline \multicolumn{6}{|l|}{ Treatment } \\
\hline Honors degree/top performance ${ }^{b}$ & 0.30 & 0.46 & 0.23 & 0.42 & $0.076^{* * *}$ \\
\hline First bar exam score & 7.70 & 2.22 & . & . & \\
\hline University grade point average & . & . & 2.24 & 0.57 & \\
\hline \multicolumn{6}{|l|}{ Demographics } \\
\hline Female & 0.46 & 0.50 & 0.64 & 0.48 & $-0.185^{* * *}$ \\
\hline Age at graduation & 25.82 & 2.28 & 27.36 & 2.51 & $-1.535^{* * *}$ \\
\hline Children at graduation & 0.04 & 0.20 & 0.11 & 0.32 & $-0.072^{* * *}$ \\
\hline Apprenticeship completed & 0.18 & 0.38 & 0.20 & 0.40 & -0.023 \\
\hline University: western Germany & 0.87 & 0.34 & 0.76 & 0.43 & $0.109^{* * *}$ \\
\hline University: eastern Germany & 0.12 & 0.32 & 0.24 & 0.43 & $-0.120^{* * *}$ \\
\hline University: abroad & 0.01 & 0.10 & 0.00 & 0.00 & $0.011^{* * *}$ \\
\hline Duration of studies (in semesters) & 10.40 & 1.95 & 12.74 & 2.22 & $-2.345^{* * *}$ \\
\hline Motivation study choice ${ }^{c}$ & 3.31 & 1.21 & 3.94 & 1.18 & $-0.628^{* * *}$ \\
\hline High school grade & 2.06 & 0.61 & 1.97 & 0.61 & $0.092^{* * *}$ \\
\hline High school: West Germany & 0.86 & 0.35 & 0.84 & 0.37 & 0.019 \\
\hline High school: East Germany & 0.14 & 0.34 & 0.15 & 0.36 & -0.014 \\
\hline High school: abroad & 0.00 & 0.07 & 0.01 & 0.10 & -0.005 \\
\hline \multicolumn{6}{|l|}{ Father's school education } \\
\hline University entrance degree & 0.49 & 0.50 & 0.53 & 0.50 & $-0.038^{*}$ \\
\hline College entrance degree & 0.10 & 0.30 & 0.12 & 0.32 & -0.021 \\
\hline Intermediate-track school degree & 0.18 & 0.38 & 0.14 & 0.34 & $0.041^{* *}$ \\
\hline Low-track school degree & 0.22 & 0.41 & 0.20 & 0.40 & 0.017 \\
\hline No school degree & 0.01 & 0.10 & 0.01 & 0.08 & 0.003 \\
\hline \multicolumn{6}{|l|}{ Mother's school education } \\
\hline University entrance degree & 0.31 & 0.46 & 0.37 & 0.48 & $-0.061^{* * *}$ \\
\hline College entrance degree & 0.05 & 0.21 & 0.06 & 0.24 & -0.011 \\
\hline Intermediate-track school degree & 0.36 & 0.48 & 0.31 & 0.46 & $0.050^{* *}$ \\
\hline Low-track school degree & 0.26 & 0.44 & 0.24 & 0.43 & 0.018 \\
\hline No school degree & 0.01 & 0.11 & 0.01 & 0.10 & 0.002 \\
\hline \multicolumn{6}{|c|}{ Father's job qualification/highest educational degree } \\
\hline University & 0.43 & 0.50 & 0.48 & 0.50 & $-0.055^{* *}$ \\
\hline College & 0.16 & 0.37 & 0.16 & 0.37 & 0.001 \\
\hline Fachschule (GDR) & 0.00 & 0.06 & 0.01 & 0.09 & -0.004 \\
\hline Trade and technical school & 0.12 & 0.32 & 0.12 & 0.32 & -0.000 \\
\hline
\end{tabular}


... continued from previous page

\begin{tabular}{lccccc}
\hline Apprenticeship & 0.25 & 0.43 & 0.20 & 0.40 & $0.051^{* * *}$ \\
No further degree & 0.02 & 0.15 & 0.02 & 0.14 & 0.003 \\
Mother's job qualification/highest educational & degree & & & \\
University & 0.24 & 0.43 & 0.30 & 0.46 & $-0.055^{* * *}$ \\
College & 0.06 & 0.24 & 0.07 & 0.25 & -0.006 \\
Fachschule (GDR) & 0.02 & 0.14 & 0.03 & 0.16 & -0.006 \\
Trade and technical school & 0.05 & 0.21 & 0.05 & 0.22 & -0.005 \\
Apprenticeship & 0.49 & 0.50 & 0.43 & 0.49 & $0.062^{* * *}$ \\
No further degree & 0.12 & 0.32 & 0.11 & 0.31 & 0.007 \\
Father's job situation & & & & & \\
Self-employed & 0.23 & 0.42 & 0.28 & 0.45 & $-0.054^{* * *}$ \\
Employee & 0.38 & 0.49 & 0.37 & 0.48 & 0.007 \\
Civil servant & 0.29 & 0.45 & 0.25 & 0.43 & $0.044^{* *}$ \\
Worker & 0.08 & 0.27 & 0.07 & 0.26 & 0.006 \\
Economically inactive & 0.02 & 0.15 & 0.02 & 0.14 & 0.003 \\
Mother's job situation & & & & & \\
Self-employed & 0.10 & 0.29 & 0.14 & 0.34 & $-0.042^{* * *}$ \\
Employee & 0.57 & 0.50 & 0.57 & 0.50 & -0.000 \\
Civil servant & 0.14 & 0.34 & 0.12 & 0.33 & 0.015 \\
Worker & 0.07 & 0.26 & 0.07 & 0.25 & 0.005 \\
Economically inactive & 0.13 & 0.33 & 0.10 & 0.30 & $0.030^{* *}$ \\
Cohort indicators & & & & & \\
Cohort 2005 & 0.15 & 0.35 & 0.30 & 0.46 & $-0.156^{* * *}$ \\
Cohort 2001 & 0.18 & 0.39 & 0.22 & 0.42 & $-0.040^{* *}$ \\
Cohort 1997 & 0.29 & 0.45 & 0.25 & 0.43 & $0.041^{* *}$ \\
Cohort 1993 & 0.38 & 0.49 & 0.23 & 0.42 & $0.154^{* * *}$ \\
\hline Number of individuals & 828 & & 1,371 & & \\
\hline
\end{tabular}

Notes: The table reports means and standard deviations (Sd) by field of study. Column 5 reports the results from two-sample mean comparison tests. ${ }^{a}$ The sample is restricted to observations with monthly gross earnings larger than 1000 euros. Monthly gross earnings are adjusted for prices in 2010. ${ }^{b}$ The treatment status (honors degree/top performance) is determined by the score of the first bar exam for law graduates and by the university grade point average for medicine and pharmacy graduates. Note that different grading scales are used in law and medicine and pharmacy. An honors degree is formally awarded in law only. We synthetically define an honors degree status for the very best of medicine and pharmacy graduates by comparing the distribution of the university grade point average with the distribution of the first bar exam score. ${ }^{c}$ The variable "motivation study choice" measures how important labor market aspects were with respect to study choice, measured on a five-point scale with 1 indicating "very important" and 5 "unimportant". Significance levels: ${ }^{*} p<0.10,{ }^{* *} p<0.05,{ }^{* * *} p<0.01$. 
Table 2: Baseline results - models using the selection on observables assumption

\begin{tabular}{|c|c|c|c|c|c|}
\hline & \multicolumn{4}{|c|}{ Log of monthly gross earnings } & \multirow{3}{*}{$\frac{\text { ENTROPY }}{(5)}$} \\
\hline & \multicolumn{2}{|c|}{ OLS } & \multirow{2}{*}{$\begin{array}{c}\text { FILM } \\
(3)\end{array}$} & \multirow{2}{*}{$\frac{\text { PSMATCH }}{(4)}$} & \\
\hline & $(1)$ & (2) & & & \\
\hline Honors & $\begin{array}{l}0.218^{* * *} \\
(0.035)\end{array}$ & $\begin{array}{l}0.125^{* * *} \\
(0.036)\end{array}$ & $\begin{array}{l}0.132^{* * *} \\
(0.040)\end{array}$ & $\begin{array}{l}0.144^{* * *} \\
(0.050)\end{array}$ & $\begin{array}{l}0.134^{* * *} \\
(0.041)\end{array}$ \\
\hline $\begin{array}{l}\mathrm{R}^{2} \\
\text { Number of individuals }\end{array}$ & $\begin{array}{c}0.049 \\
828\end{array}$ & $\begin{array}{c}0.194 \\
828\end{array}$ & $\begin{array}{c}0.237 \\
828\end{array}$ & $\begin{array}{c}0.017 \\
819\end{array}$ & $\begin{array}{c}0.192 \\
828\end{array}$ \\
\hline High school grade & No & Yes & Yes & Yes & Yes \\
\hline Duration of studies & No & Yes & Yes & Yes & Yes \\
\hline Motivation study choice & No & Yes & Yes & Yes & Yes \\
\hline Parental Background & No & Yes & Yes & Yes & Yes \\
\hline Further controls & No & Yes & Yes & Yes & Yes \\
\hline Cohort indicators & No & Yes & Yes & Yes & Yes \\
\hline
\end{tabular}

Notes: Each estimated coefficient (standard error) comes from a different regression. Robust standard errors in parentheses. Columns 1-2 display the results from simple OLS regressions with different sets of control variables. Column 3 presents estimates of the fully interacted linear model and column 4 displays the propensity score matching results. Entropy balancing results are reported in column 5 . For matching, radius matching with a caliper of 0.01 is used discarding observations without common support. Standard errors in column 4 are bootstrapped with 1,000 replications. The Pseudo- $\mathrm{R}^{2}$ after matching is reported in column 4. For entropy balancing, law graduates without an honors degree are reweighted such that the means, variances and skewness of the control variables resemble those of law graduates with an honors degree. Monthly gross earnings are measured five to six years after graduation. High school grade and duration of studies (in semesters) are included linearly and quadratically. Motivation of study choice with respect to labor market aspects is included linearly. The control variables are measured one year after graduation and include the respondent's gender, location of high school (eastern Germany, western Germany, abroad), completion of an apprenticeship before studying, location of university (eastern Germany, western Germany, abroad), age at graduation, child at graduation, and the highest general school degree, job qualifications and employment status of both parents. Significance levels: ${ }^{*} p<0.10,{ }^{* *} p<0.05,{ }^{* * *} p<0.01$. 
Table 3: Main results

\begin{tabular}{|c|c|c|c|c|}
\hline & \multicolumn{4}{|c|}{ Log of monthly gross earnings } \\
\hline & \multicolumn{2}{|c|}{ Difference-in-differences } & \multicolumn{2}{|c|}{ DiD \& entropy balancing } \\
\hline & $(1)$ & $(2)$ & $(3)$ & (4) \\
\hline Honors & $\begin{array}{c}0.013 \\
(0.030)\end{array}$ & $\begin{array}{r}-0.010 \\
(0.029)\end{array}$ & $\begin{array}{c}0.004 \\
(0.034)\end{array}$ & $\begin{array}{c}0.004 \\
(0.030)\end{array}$ \\
\hline Law & $\begin{array}{c}-0.202^{* * *} \\
(0.022)\end{array}$ & $\begin{array}{c}-0.233^{* * *} \\
(0.028)\end{array}$ & $\begin{array}{c}-0.127^{* * *} \\
(0.042)\end{array}$ & $\begin{array}{c}-0.189^{* * *} \\
(0.045)\end{array}$ \\
\hline Honors*Law & $\begin{array}{l}0.205^{* * *} \\
(0.046)\end{array}$ & $\begin{array}{c}0.174^{* * *} \\
(0.045)\end{array}$ & $\begin{array}{l}0.130^{* *} \\
(0.058)\end{array}$ & $\begin{array}{c}0.130^{* *} \\
(0.054)\end{array}$ \\
\hline $\mathrm{R}^{2}$ & 0.040 & 0.162 & 0.014 & 0.154 \\
\hline Number of individuals & 2,199 & 2,199 & 2,199 & 2,199 \\
\hline High school grade & No & Yes & No & Yes \\
\hline Duration of studies & No & Yes & No & Yes \\
\hline Motivation study choice & No & Yes & No & Yes \\
\hline Parental background & No & Yes & No & Yes \\
\hline Further controls & No & Yes & No & Yes \\
\hline Cohort indicators & No & Yes & No & Yes \\
\hline
\end{tabular}

Notes: The table presents the results from 4 separate difference-in-differences specifications comparing law graduates to medicine and pharmacy graduates. Columns 1 and 2 display the results from simple difference-in-differences specifications, and columns 3 and 4 show the results from the difference-in-differences combined with entropy balancing specifications. For each regression, the estimates of obtaining an honors degree in law or being among the best graduates in medicine or pharmacy, respectively (Honors), being a law graduate (Law) and the interaction term of both variables (Honors*Law) are reported. In columns 3 and 4, law graduates without an honors degree are reweighted by using entropy balancing such that the means, variances and skewness of the control variables resemble those of law graduates with an honors degree, and medicine and pharmacy graduates are reweighted accordingly. Standard errors are reported in parentheses. Robust standard errors are reported in columns 1 and 2, and linearized standard errors are reported in columns 3 and 4. Monthly gross earnings are measured five to six years after graduation. High school grade and duration of studies (in semesters) are included linearly and quadratically. Motivation of study choice with respect to labor market aspects is included linearly. The control variables are measured one year after graduation and include the respondent's gender, location of high school (eastern Germany, western Germany, abroad), completion of an apprenticeship before studying, location of university (eastern Germany, western Germany, abroad), age at graduation, child at graduation, and the highest general school degree, job qualifications and employment status of both parents. Significance levels: ${ }^{*} p<0.10,{ }^{* *} p<0.05,{ }^{* * *} p<0.01$. 


\section{A Appendix. Supplementary Figures and Tables (intended as Online Appendix)}

Figure A-1: DZHW panel survey of graduates

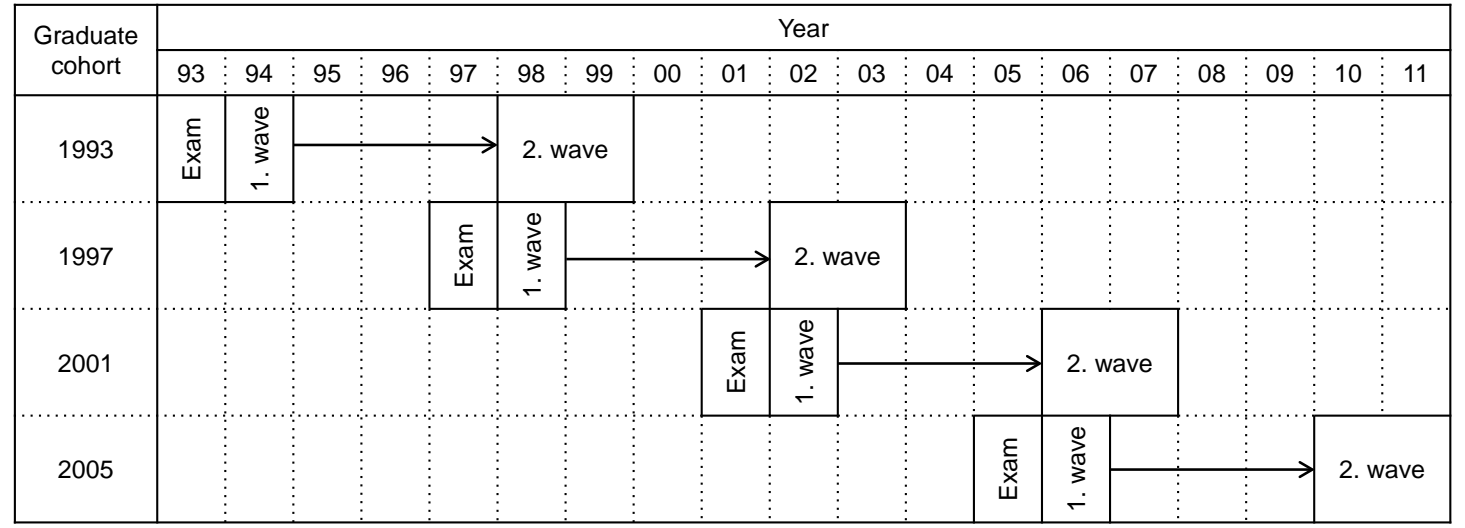

Notes: The figure highlights the data structure of the DZHW panel survey of graduates. Graduates are interviewed about their studies and other topics one year after graduation. They are interviewed again five to six years after graduation about their labor market experience and several other topics. In the analysis, the graduate cohorts of the years 1993, 1997, 2001 and 2005 are used. Own illustration based on Briedis (2007). 
Figure A-2: Matching quality - Common support

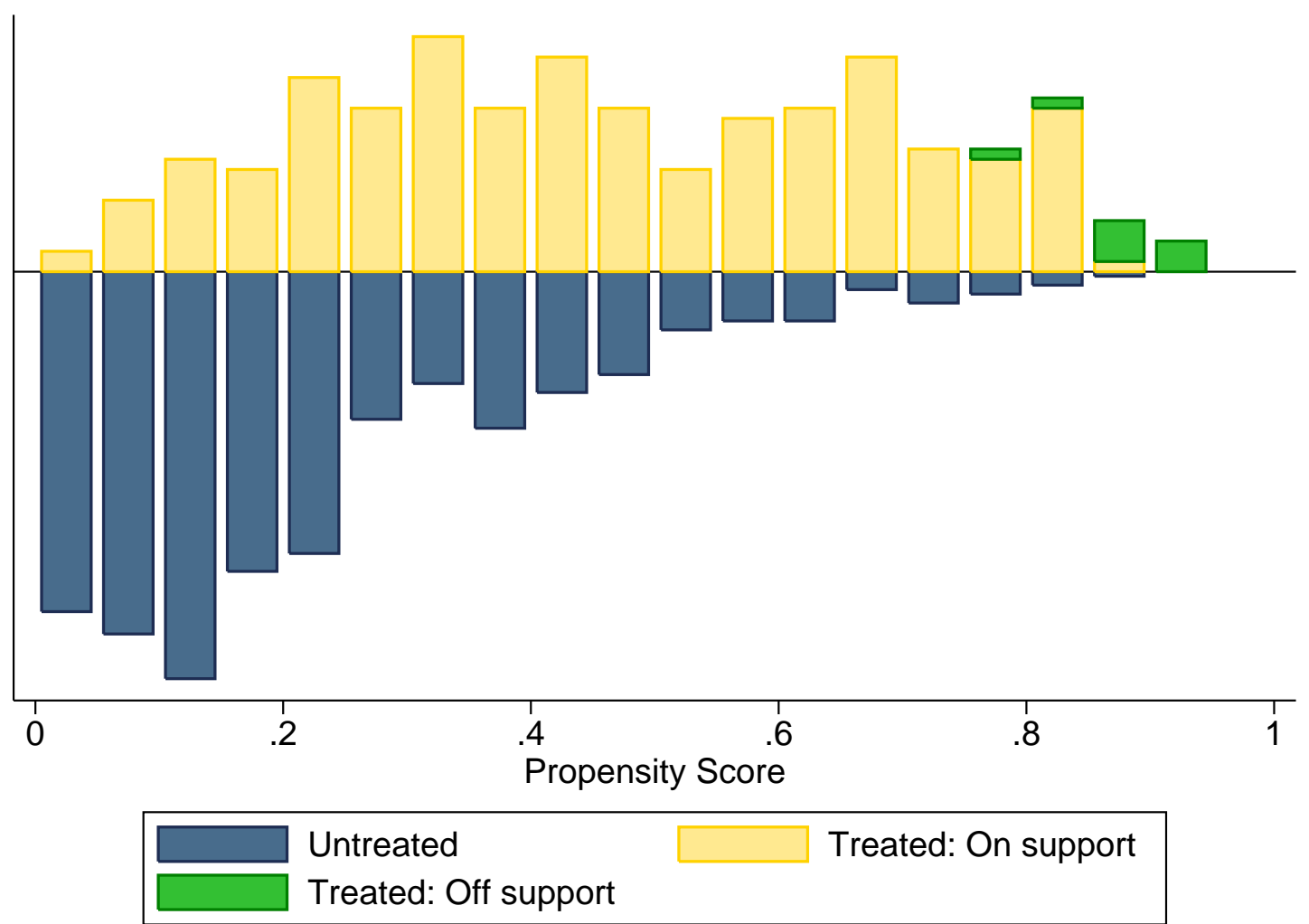

Notes: The figure displays the propensity score histogram of the propensity score matching specification as reported in Table 2, column 5. The histogram shows how many individuals are on and off the common support based on the estimated propensity score. The blue and yellow bars indicate how many observations in the treated and untreated groups could be successfully matched with each other. The green bars indicate how many observations could not be matched, i.e. how many observations are off the common support. 
Table A-1: Baseline results - OLS with covariates

\begin{tabular}{|c|c|c|}
\hline & \multicolumn{2}{|c|}{ Log of monthly gross earnings } \\
\hline & (1) & $(2)$ \\
\hline Honors degree & $0.125^{* * *}$ & $(0.036)$ \\
\hline Female & $-0.128^{* * *}$ & $(0.032)$ \\
\hline \multicolumn{3}{|l|}{ School education } \\
\hline High school grade & $-0.298^{*}$ & $(0.164)$ \\
\hline Squared high school grade & 0.053 & $(0.036)$ \\
\hline High school: East Germany & 0.030 & $(0.084)$ \\
\hline High school: foreign & $0.572^{* * *}$ & $(0.075)$ \\
\hline \multicolumn{3}{|l|}{ Studies } \\
\hline Apprenticeship completed & $0.202^{* * *}$ & $(0.047)$ \\
\hline Age at graduation & -0.062 & $(0.042)$ \\
\hline Age at graduation squared & 0.001 & $(0.001)$ \\
\hline Duration of studies & -0.047 & $(0.029)$ \\
\hline Duration of studies squared & $0.002^{*}$ & $(0.001)$ \\
\hline Motivation study choice & -0.015 & $(0.012)$ \\
\hline University: eastern Germany & $-0.295^{* * *}$ & $(0.086)$ \\
\hline Children at graduation & -0.080 & $(0.062)$ \\
\hline \multicolumn{3}{|l|}{ Father's school education } \\
\hline University entrance degree & 0.009 & $(0.065)$ \\
\hline College entrance degree & -0.082 & $(0.066)$ \\
\hline Intermediate-track school degree & -0.021 & $(0.050)$ \\
\hline \multicolumn{3}{|l|}{ Mother's school education } \\
\hline University entrance degree & 0.083 & $(0.063)$ \\
\hline College entrance degree & 0.009 & $(0.100)$ \\
\hline Intermediate-track school degree & 0.061 & $(0.040)$ \\
\hline \multicolumn{3}{|l|}{ Father's job qualification } \\
\hline University & 0.042 & $(0.066)$ \\
\hline College & 0.014 & $(0.055)$ \\
\hline Fachschule (GDR) & 0.096 & $(0.132)$ \\
\hline Trade and technical school & 0.034 & $(0.049)$ \\
\hline \multicolumn{3}{|l|}{ Mother's job qualification } \\
\hline University & 0.072 & $(0.067)$ \\
\hline College & -0.069 & $(0.081)$ \\
\hline Fachschule (GDR) & -0.095 & $(0.133)$ \\
\hline Trade and technical school & 0.089 & $(0.076)$ \\
\hline \multicolumn{3}{|l|}{ Father's job situation } \\
\hline Self-employed & 0.046 & $(0.061)$ \\
\hline Employee & 0.072 & $(0.056)$ \\
\hline Civil servant & 0.021 & $(0.059)$ \\
\hline Mother's job situation & & \\
\hline
\end{tabular}

continued on next page ... 
.. continued from previous page

Log of monthly gross earnings

(1) (2)

\begin{tabular}{lcc}
\hline Self-employed & -0.054 & $(0.063)$ \\
Employee & 0.007 & $(0.038)$ \\
Civil servant & -0.035 & $(0.061)$ \\
Cohort indicators & & \\
Cohort 2005 & -0.043 & $(0.045)$ \\
Cohort 2001 & -0.064 & $(0.045)$ \\
Cohort 1997 & -0.031 & $(0.039)$ \\
Constant & $9.835^{* * *}$ & $(0.680)$ \\
\hline Observations & 828 & \\
$\mathrm{R}^{2}$ & 0.19 & \\
\hline
\end{tabular}

Notes: The table reports all estimated coefficients (column 1) and robust standard errors (column 2) from the OLS regressions Table 2, column 2. Significance levels: ${ }^{*} p<0.10,{ }^{* *} p<0.05,{ }^{* * *} p<0.01$. 
Table A-2: Entropy balancing moments - law graduates

\begin{tabular}{|c|c|c|c|c|c|c|}
\hline & \multicolumn{2}{|c|}{ Treatment group } & \multicolumn{4}{|c|}{ Control group } \\
\hline & \multirow{3}{*}{$\frac{\text { Mean }}{(1)}$} & \multirow{3}{*}{$\frac{\text { Variance }}{(2)}$} & \multicolumn{2}{|c|}{ Before balancing } & \multicolumn{2}{|c|}{ After balancing } \\
\hline & & & Mean & Variance & Mean & Variance \\
\hline & & & $(3)$ & $(4)$ & $(5)$ & $(6)$ \\
\hline \multicolumn{7}{|l|}{ Demographics } \\
\hline Female & 0.39 & 0.24 & 0.49 & 0.25 & 0.39 & 0.24 \\
\hline Age at graduation & 25.42 & 2.52 & 26.00 & 6.27 & 25.42 & 2.52 \\
\hline Children at graduation & 0.03 & 0.03 & 0.05 & 0.05 & 0.03 & 0.03 \\
\hline Apprenticeship completed & 0.18 & 0.15 & 0.18 & 0.15 & 0.18 & 0.15 \\
\hline University: western Germany & 0.89 & 0.10 & 0.86 & 0.12 & 0.89 & 0.10 \\
\hline University: eastern Germany & 0.09 & 0.08 & 0.13 & 0.12 & 0.09 & 0.08 \\
\hline Duration of studies (in semesters) & 9.86 & 1.81 & 10.64 & 4.50 & 9.86 & 1.81 \\
\hline Motivation study choice & 3.36 & 1.41 & 3.29 & 1.49 & 3.36 & 1.41 \\
\hline High school grade & 1.69 & 0.27 & 2.23 & 0.33 & 1.69 & 0.27 \\
\hline High school: western Germany & 0.89 & 0.10 & 0.84 & 0.13 & 0.89 & 0.10 \\
\hline High school: eastern Germany & 0.10 & 0.09 & 0.16 & 0.13 & 0.10 & 0.09 \\
\hline \multicolumn{7}{|l|}{ Father's highest general school degree } \\
\hline University entrance degree & 0.53 & 0.25 & 0.47 & 0.25 & 0.53 & 0.25 \\
\hline College entrance degree & 0.07 & 0.07 & 0.11 & 0.10 & 0.07 & 0.07 \\
\hline Intermediate-track school degree & 0.17 & 0.14 & 0.18 & 0.15 & 0.17 & 0.14 \\
\hline Low-track school degree & 0.22 & 0.17 & 0.21 & 0.17 & 0.22 & 0.17 \\
\hline No school degree & 0.00 & 0.00 & 0.01 & 0.01 & 0.00 & 0.00 \\
\hline \multicolumn{7}{|l|}{ Mother's highest general school degree } \\
\hline University entrance degree & 0.37 & 0.23 & 0.29 & 0.20 & 0.37 & 0.23 \\
\hline College entrance degree & 0.04 & 0.04 & 0.05 & 0.05 & 0.04 & 0.04 \\
\hline Intermediate-track school degree & 0.34 & 0.22 & 0.37 & 0.23 & 0.34 & 0.22 \\
\hline Low-track school degree & 0.25 & 0.19 & 0.27 & 0.20 & 0.25 & 0.19 \\
\hline No school degree & 0.01 & 0.01 & 0.01 & 0.01 & 0.01 & 0.01 \\
\hline \multicolumn{7}{|c|}{ Father's job qualification/highest educational degree } \\
\hline University & 0.50 & 0.25 & 0.40 & 0.24 & 0.50 & 0.25 \\
\hline College & 0.13 & 0.11 & 0.18 & 0.15 & 0.13 & 0.11 \\
\hline Fachschule (GDR) & 0.00 & 0.00 & 0.00 & 0.00 & 0.00 & 0.00 \\
\hline Trade and technical school & 0.09 & 0.08 & 0.13 & 0.11 & 0.09 & 0.08 \\
\hline Apprenticeship & 0.25 & 0.19 & 0.25 & 0.19 & 0.25 & 0.19 \\
\hline No further degree & 0.01 & 0.01 & 0.03 & 0.03 & 0.01 & 0.01 \\
\hline \multicolumn{7}{|c|}{ Mother's job qualification/highest educational degree } \\
\hline University & 0.28 & 0.20 & 0.23 & 0.18 & 0.28 & 0.20 \\
\hline College & 0.07 & 0.06 & 0.06 & 0.06 & 0.07 & 0.06 \\
\hline Fachschule (GDR) & 0.02 & 0.02 & 0.02 & 0.02 & 0.02 & 0.02 \\
\hline Trade and technical school & 0.04 & 0.04 & 0.05 & 0.05 & 0.04 & 0.04 \\
\hline
\end{tabular}




\begin{tabular}{|c|c|c|c|c|c|c|}
\hline & \multicolumn{2}{|c|}{ Treatment group } & \multicolumn{4}{|c|}{ Control group } \\
\hline & \multirow[b]{2}{*}{ Mean } & \multirow[b]{2}{*}{ Variance } & \multicolumn{2}{|c|}{ Before balancing } & \multicolumn{2}{|c|}{ After balancing } \\
\hline & & & Mean & Variance & Mean & Variance \\
\hline & (1) & $(2)$ & $(3)$ & $(4)$ & $(5)$ & (6) \\
\hline Apprenticeship & 0.47 & 0.25 & 0.50 & 0.25 & 0.47 & 0.25 \\
\hline No further degree & 0.12 & 0.11 & 0.12 & 0.10 & 0.12 & 0.11 \\
\hline \multicolumn{7}{|c|}{ Father's employment status } \\
\hline Self-employed & 0.20 & 0.16 & 0.24 & 0.18 & 0.20 & 0.16 \\
\hline Employee & 0.34 & 0.23 & 0.40 & 0.24 & 0.34 & 0.23 \\
\hline Civil servant & 0.36 & 0.23 & 0.26 & 0.19 & 0.36 & 0.23 \\
\hline Worker & 0.08 & 0.07 & 0.08 & 0.07 & 0.08 & 0.07 \\
\hline \multicolumn{7}{|c|}{ Mother's employment status } \\
\hline Self-employed & 0.09 & 0.08 & 0.10 & 0.09 & 0.09 & 0.08 \\
\hline Employee & 0.55 & 0.25 & 0.58 & 0.24 & 0.55 & 0.25 \\
\hline Civil servant & 0.07 & 0.06 & 0.08 & 0.07 & 0.07 & 0.06 \\
\hline Worker & 0.12 & 0.11 & 0.13 & 0.11 & 0.12 & 0.11 \\
\hline \multicolumn{7}{|l|}{ Cohort indicators } \\
\hline Cohort 2005 & 0.15 & 0.13 & 0.15 & 0.13 & 0.15 & 0.13 \\
\hline Cohort 2001 & 0.21 & 0.16 & 0.17 & 0.14 & 0.21 & 0.16 \\
\hline Cohort 1997 & 0.31 & 0.22 & 0.28 & 0.20 & 0.31 & 0.21 \\
\hline
\end{tabular}

Notes: The table shows the control variables' means and variances for law graduates. The means and variances of the control variables are reported for graduates with an honors degree, for graduates without an honors degree before balancing, and for graduates without an honors degree after balancing. Law graduates without an honors degree are reweighted such that their group means, variances and skewness resemble the means, variances and skewness of the group of law graduates with an honors degree. The skewness of the control variable is not reported. The variables "University: abroad", "High school: abroad", "Father's employment status: economically inactive" and "Mother's employment status: economically inactive" are excluded from balancing because of collinearity. 
Table A-3: Entropy balancing moments - medicine \& pharmacy graduates

\begin{tabular}{|c|c|c|c|c|c|c|}
\hline & \multicolumn{2}{|c|}{ Treatment group } & \multicolumn{4}{|c|}{ Control group } \\
\hline & \multirow{3}{*}{$\frac{\text { Mean }}{(1)}$} & \multirow{3}{*}{$\frac{\text { Variance }}{(2)}$} & \multicolumn{2}{|c|}{ Before balancing } & \multicolumn{2}{|c|}{ After balancing } \\
\hline & & & Mean & Variance & Mean & Variance \\
\hline & & & $(3)$ & $(4)$ & $(5)$ & $(6)$ \\
\hline \multicolumn{7}{|l|}{ Demographics } \\
\hline Female & 0.69 & 0.22 & 0.63 & 0.23 & 0.69 & 0.22 \\
\hline Age at graduation & 26.58 & 3.75 & 27.59 & 6.82 & 26.58 & 3.75 \\
\hline Children at graduation & 0.07 & 0.07 & 0.13 & 0.11 & 0.07 & 0.07 \\
\hline Apprenticeship completed & 0.15 & 0.13 & 0.22 & 0.17 & 0.15 & 0.13 \\
\hline University: western Germany & 0.76 & 0.18 & 0.76 & 0.18 & 0.76 & 0.18 \\
\hline Duration of studies (in semesters) & 12.35 & 4.27 & 12.86 & 5.09 & 12.35 & 4.27 \\
\hline Motivation study choice & 3.89 & 1.31 & 3.96 & 1.42 & 3.89 & 1.31 \\
\hline High school grade & 1.68 & 0.27 & 2.06 & 0.37 & 1.68 & 0.27 \\
\hline High school: western Germany & 0.84 & 0.14 & 0.84 & 0.14 & 0.84 & 0.13 \\
\hline High school: eastern Germany & 0.15 & 0.13 & 0.15 & 0.13 & 0.15 & 0.13 \\
\hline \multicolumn{7}{|l|}{ Father's highest general school degree } \\
\hline University entrance degree & 0.59 & 0.24 & 0.51 & 0.25 & 0.59 & 0.24 \\
\hline College entrance degree & 0.13 & 0.11 & 0.12 & 0.10 & 0.13 & 0.11 \\
\hline Intermediate-track school degree & 0.12 & 0.11 & 0.14 & 0.12 & 0.12 & 0.11 \\
\hline Low-track school degree & 0.16 & 0.14 & 0.21 & 0.17 & 0.16 & 0.13 \\
\hline No school degree & 0.00 & 0.00 & 0.01 & 0.01 & 0.00 & 0.00 \\
\hline \multicolumn{7}{|l|}{ Mother's highest general school degree } \\
\hline University entrance degree & 0.45 & 0.25 & 0.35 & 0.23 & 0.45 & 0.25 \\
\hline College entrance degree & 0.05 & 0.04 & 0.06 & 0.06 & 0.05 & 0.04 \\
\hline Intermediate-track school degree & 0.32 & 0.22 & 0.31 & 0.21 & 0.32 & 0.22 \\
\hline Low-track school degree & 0.19 & 0.15 & 0.26 & 0.19 & 0.19 & 0.15 \\
\hline No school degree & 0.00 & 0.00 & 0.01 & 0.01 & 0.00 & 0.00 \\
\hline \multicolumn{7}{|c|}{ Father's job qualification/highest educational degree } \\
\hline University & 0.54 & 0.25 & 0.47 & 0.25 & 0.54 & 0.25 \\
\hline College & 0.15 & 0.13 & 0.16 & 0.14 & 0.15 & 0.13 \\
\hline Fachschule (GDR) & 0.01 & 0.01 & 0.01 & 0.01 & 0.01 & 0.01 \\
\hline Trade and technical school & 0.08 & 0.07 & 0.13 & 0.11 & 0.08 & 0.07 \\
\hline Apprenticeship & 0.20 & 0.16 & 0.20 & 0.16 & 0.20 & 0.16 \\
\hline No degree & 0.01 & 0.01 & 0.02 & 0.02 & 0.01 & 0.01 \\
\hline \multicolumn{7}{|c|}{ Mother's job qualification/highest educational degree } \\
\hline University & 0.38 & 0.24 & 0.28 & 0.20 & 0.38 & 0.24 \\
\hline College & 0.07 & 0.07 & 0.07 & 0.06 & 0.07 & 0.07 \\
\hline Fachschule (GDR) & 0.03 & 0.03 & 0.03 & 0.03 & 0.03 & 0.03 \\
\hline Trade and technical school & 0.04 & 0.03 & 0.06 & 0.05 & 0.04 & 0.03 \\
\hline Apprenticeship & 0.38 & 0.24 & 0.44 & 0.25 & 0.38 & 0.24 \\
\hline
\end{tabular}




\begin{tabular}{|c|c|c|c|c|c|c|}
\hline & \multicolumn{2}{|c|}{ Treatment group } & \multicolumn{4}{|c|}{ Control group } \\
\hline & \multirow[b]{2}{*}{ Mean } & \multirow[b]{2}{*}{ Variance } & \multicolumn{2}{|c|}{ Before balancing } & \multicolumn{2}{|c|}{ After balancing } \\
\hline & & & Mean & Variance & Mean & Variance \\
\hline & (1) & $(2)$ & $(3)$ & (4) & $(5)$ & (6) \\
\hline No degree & 0.09 & 0.08 & 0.12 & 0.11 & 0.09 & 0.08 \\
\hline \multicolumn{7}{|c|}{ Father's employment status } \\
\hline Self-employed & 0.25 & 0.19 & 0.29 & 0.21 & 0.25 & 0.19 \\
\hline Employee & 0.40 & 0.24 & 0.37 & 0.23 & 0.40 & 0.24 \\
\hline Civil servant & 0.28 & 0.20 & 0.24 & 0.18 & 0.28 & 0.20 \\
\hline Worker & 0.06 & 0.06 & 0.08 & 0.07 & 0.06 & 0.06 \\
\hline Economically inactive & 0.01 & 0.01 & 0.02 & 0.02 & 0.01 & 0.01 \\
\hline \multicolumn{7}{|c|}{ Mother's employment status } \\
\hline Self-employed & 0.12 & 0.10 & 0.14 & 0.12 & 0.12 & 0.10 \\
\hline Employee & 0.61 & 0.24 & 0.56 & 0.25 & 0.61 & 0.24 \\
\hline Civil servant & 0.15 & 0.13 & 0.11 & 0.10 & 0.15 & 0.13 \\
\hline Worker & 0.05 & 0.05 & 0.07 & 0.07 & 0.05 & 0.05 \\
\hline Economically inactive & 0.06 & 0.05 & 0.11 & 0.10 & 0.06 & 0.05 \\
\hline \multicolumn{7}{|l|}{ Cohort indicators } \\
\hline Cohort 2005 & 0.35 & 0.23 & 0.29 & 0.21 & 0.35 & 0.23 \\
\hline Cohort 2001 & 0.24 & 0.18 & 0.22 & 0.17 & 0.24 & 0.18 \\
\hline Cohort 1997 & 0.27 & 0.20 & 0.24 & 0.18 & 0.27 & 0.20 \\
\hline
\end{tabular}

Notes: The table shows the control variables' means and variances for medicine and pharmacy graduates. The means and variances of the control variables are reported for graduates with a pseudo honors degree (top performance), for graduates without a pseudo honors degree before balancing, and for graduates without a pseudo honors degree after balancing. Medicine and pharmacy graduates without a pseudo honors degree are reweighted such that their group means, variances and skewness resemble the means, variances and skewness of the group of medicine and pharmacy graduates with a pseudo honors degree. The skewness of the control variable is not reported. The variables "University: eastern Germany", "University: abroad" and "High school: abroad" are excluded from balancing because of collinearity. 
Table A-4: Robustness of matching and entropy balancing results

\begin{tabular}{|c|c|c|c|c|c|c|c|}
\hline & Rad 0.05 & Rad 0.15 & $\mathrm{NN}-5$ & Kernel & Mahal & Entropy-I & Entropy-II \\
\hline & $(1)$ & $(2)$ & $(3)$ & (4) & (5) & (6) & (7) \\
\hline \multirow[b]{2}{*}{ Honors } & \multicolumn{7}{|c|}{ Log of monthly gross earnings } \\
\hline & $\begin{array}{l}0.144^{* * *} \\
(0.051)\end{array}$ & $\begin{array}{l}0.150^{* * *} \\
(0.049)\end{array}$ & $\begin{array}{l}0.145^{* * *} \\
(0.052)\end{array}$ & $\begin{array}{l}0.150^{* * *} \\
(0.049)\end{array}$ & $\begin{array}{l}0.146^{* * *} \\
(0.049)\end{array}$ & $\begin{array}{l}0.138^{* * *} \\
(0.042)\end{array}$ & $\begin{array}{l}0.146^{* * *} \\
(0.040)\end{array}$ \\
\hline $\mathrm{N}$ & 791 & 822 & 819 & 823 & 828 & 828 & 828 \\
\hline
\end{tabular}

Notes: Columns 1 and 2 show results for radius matching in which we have subtracted and added 0.005 to our baseline caliper of 0.01 . In column 3 , nearest-neighbor matching using up to 5 neighbors within a caliper of 0.01 is deployed. Results in column 4 use a kernel matching procedure with a bandwidth of 0.02 and a Epanechnikov kernel. In column 5 Mahalanobis distance matching is used. In columns 6 and 7 , the results for entropy balancing are shown using the mean and variance only, and the mean only, respectively, when balancing covariate moments between the treatment and the control group. Standard errors for the matching estimators in columns 1 to 5 are bootstrapped with 1,000 replications; standard errors in columns 6 and 7 are linearized. Note that the number of observations varies because each specification differs in the common support. The control variables are measured one year after graduation and include the respondent's gender, high school grade, location of high school (eastern Germany, western Germany, abroad), completion of an apprenticeship before studying, location of university (eastern Germany, western Germany, abroad), age at graduation, child at graduation, duration of studies (in semesters), motivation study choice, and the highest general school degree, job qualifications and employment status of both parents. Significance levels: $* p<0.10,{ }^{* *} p<0.05,{ }^{* * *} p<0.01$. 
Table A-5: Difference-in-differences - omitting graduates ranked in the $41-50$ percentiles

\begin{tabular}{|c|c|c|c|}
\hline & Reference & Random & Cut \\
\hline & $(1)$ & $(2)$ & $(3)$ \\
\hline & \multicolumn{3}{|c|}{ Panel 1: Difference-in-differences } \\
\hline Honors & $\begin{array}{c}-0.010 \\
(0.029)\end{array}$ & $\begin{array}{c}-0.021 \\
(0.030)\end{array}$ & $\begin{array}{c}-0.004 \\
(0.031)\end{array}$ \\
\hline Law & $\begin{array}{c}-0.233^{* * *} \\
(0.028)\end{array}$ & $\begin{array}{c}-0.242^{* * *} \\
(0.030)\end{array}$ & $\begin{array}{c}-0.241^{* * *} \\
(0.034)\end{array}$ \\
\hline \multirow[t]{2}{*}{ Honors*Law } & $\begin{array}{l}0.174^{* * *} \\
(0.045)\end{array}$ & $\begin{array}{l}0.181^{* * *} \\
(0.046)\end{array}$ & $\begin{array}{l}0.180^{* * *} \\
(0.048)\end{array}$ \\
\hline & \multicolumn{3}{|c|}{ Panel 2: DiD \& entropy balancing } \\
\hline Honors & $\begin{array}{c}0.004 \\
(0.030)\end{array}$ & $\begin{array}{c}-0.002 \\
(0.031)\end{array}$ & $\begin{array}{c}0.026 \\
(0.033)\end{array}$ \\
\hline Law & $\begin{array}{c}-0.189^{* * *} \\
(0.045)\end{array}$ & $\begin{array}{c}-0.178^{* * *} \\
(0.049)\end{array}$ & $\begin{array}{c}-0.156^{* * *} \\
(0.055)\end{array}$ \\
\hline Honors*Law & $\begin{array}{l}0.130^{* *} \\
(0.054)\end{array}$ & $\begin{array}{c}0.116^{* *} \\
(0.056)\end{array}$ & $\begin{array}{c}0.094 \\
(0.060)\end{array}$ \\
\hline $\mathrm{N}$ & 2,199 & 1,988 & 1,697 \\
\hline High school grade & Yes & Yes & Yes \\
\hline Duration of studies & Yes & Yes & Yes \\
\hline Motivation study choice & Yes & Yes & Yes \\
\hline Parental background & Yes & Yes & Yes \\
\hline Further controls & Yes & Yes & Yes \\
\hline Cohort fixed effects & Yes & Yes & Yes \\
\hline
\end{tabular}

Notes: Standard errors in parentheses. Robust standard errors in panel 1. Linearized standard errors in panel 2. The table presents results from difference-in-differences specifications and difference-in-differences combined with entropy balancing specifications. Column 1 presents the same result as in table 3 , columns 2 an 4 . Columns 2 and 3 omit law graduates, and medicine and pharmacy graduates who ranked among the best 41 to 50 percentile respectively to check the robustness with respect to the kink in the common trend diagram in figure 3 . In column 2 , around 50 percent of law graduates with a first bar exam score of 7 points and roughly 50 percent of medicine and pharmacy graduates with a graduation grade of 2.0 and 2.1 are randomly omitted from the sample. In column 3, all law graduates with a first bar exam score of 7 points and all medicine and pharmacy graduates with a graduation grade of 2.0 and 2.1 are omitted from the sample. Significance levels: * $p<0.10,{ }^{* *} p<0.05,{ }^{* * *} p<0.01$. 
Table A-6: Sensitivity to omitted variable bias

\begin{tabular}{lc}
\hline Description & $\begin{array}{c}\text { Estimate } \\
\text { (Std. error })\end{array}$ \\
\hline Baseline effect $\dot{\gamma}_{3}$ & 0.205 \\
& $(0.046)$ \\
R-squared $\dot{R}$ & 0.040 \\
Controlled effect $\tilde{\gamma}_{3}$ & 0.174 \\
& $(0.045)$ \\
R-squared $\tilde{R}$ & 0.162 \\
Bias-adjusted coefficient $\gamma_{3}^{*^{\prime}}$ for $\tilde{\delta}=1$ & 0.125 \\
Identified set $\left.\left[\gamma_{3}^{\star \prime}\left(\min _{2} 2.2 \tilde{R}, 1\right\}, 1\right), \tilde{\gamma_{3}}\right]$ for $\tilde{\delta}=1$ & {$[0.125,0.174]$} \\
Confidence Interval & {$\left[0.091, \tilde{\gamma}_{3}\right.$} \\
Is zero excluded from identified set? $(\tilde{\delta}=1)$ & Yes \\
Is $\gamma_{3}^{*^{\prime}}$ within 95 -confidence interval? $(\tilde{\delta}=1)$ & Yes \\
\hline
\end{tabular}

Notes: Based on an econometric method developed by Oster (2014). 
Table A-7: Difference-in-differences \& entropy balancing - alternative treatment coding in control group

\begin{tabular}{|c|c|c|c|c|c|c|}
\hline & \multicolumn{6}{|c|}{ Share of treated persons in control group } \\
\hline & 0.18 & 0.23 & 0.25 & 0.27 & 0.30 & 0.32 \\
\hline & (1) & $(2)$ & $(3)$ & (4) & $(5)$ & $(6)$ \\
\hline & \multicolumn{6}{|c|}{ Log of monthly gross earnings } \\
\hline Honors & $\begin{array}{c}0.020 \\
(0.032)\end{array}$ & $\begin{array}{c}0.004 \\
(0.030)\end{array}$ & $\begin{array}{c}-0.002 \\
(0.029)\end{array}$ & $\begin{array}{c}0.005 \\
(0.028)\end{array}$ & $\begin{array}{c}-0.016 \\
(0.027)\end{array}$ & $\begin{array}{c}-0.012 \\
(0.027)\end{array}$ \\
\hline Law & $\begin{array}{c}-0.178^{* * *} \\
(0.044)\end{array}$ & $\begin{array}{c}-0.189^{* * *} \\
(0.045)\end{array}$ & $\begin{array}{c}-0.191^{* * *} \\
(0.045)\end{array}$ & $\begin{array}{c}-0.189^{* * *} \\
(0.045)\end{array}$ & $\begin{array}{c}-0.196^{* * *} \\
(0.045)\end{array}$ & $\begin{array}{c}-0.196^{* * *} \\
(0.045)\end{array}$ \\
\hline Honors*Law & $\begin{array}{c}0.114^{* *} \\
(0.055)\end{array}$ & $\begin{array}{l}0.130^{* *} \\
(0.054)\end{array}$ & $\begin{array}{l}0.136^{* *} \\
(0.053)\end{array}$ & $\begin{array}{c}0.129^{* *} \\
(0.053)\end{array}$ & $\begin{array}{l}0.150^{* * *} \\
(0.052)\end{array}$ & $\begin{array}{l}0.146^{* * *} \\
(0.052)\end{array}$ \\
\hline High school grade & Yes & Yes & Yes & Yes & Yes & Yes \\
\hline Duration of studies & Yes & Yes & Yes & Yes & Yes & Yes \\
\hline Motivation study choice & Yes & Yes & Yes & Yes & Yes & Yes \\
\hline Parental background & Yes & Yes & Yes & Yes & Yes & Yes \\
\hline Further controls & Yes & Yes & Yes & Yes & Yes & Yes \\
\hline Cohort fixed effects & Yes & Yes & Yes & Yes & Yes & Yes \\
\hline
\end{tabular}

Notes: Robust standard errors are reported in parentheses. The table presents the diffence-in-differences results comparing law graduates to medicine and pharmacy graduates as control group using alternative treatment codings for the control group. In each column a different cutoff based the relative distribution of the university graduation grade is used. Column 2 repeats the result presented in table 3, column 4. Each column shows the estimate of obtaining an honors degree in law or being among the best graduates in medicine or pharmacy respectively (Honors), being a law graduate (Law) and the interaction term of both (Honors*Law). Significance levels: $* p<0.10, * * p<0.05, * * * p<0.01$. 
Table A-8: Difference-in-differences - omitting best law graduates

\begin{tabular}{|c|c|c|c|c|c|c|}
\hline & \multicolumn{6}{|c|}{ The sample includes law graduates with scores of } \\
\hline & All & $<15$ & $<14$ & $<13$ & $<12$ & $<11$ \\
\hline & (1) & $(2)$ & $(3)$ & $(4)$ & $(5)$ & $(6)$ \\
\hline & \multicolumn{6}{|c|}{ Panel 1: Difference-in-differences } \\
\hline Honors & $\begin{array}{c}-0.010 \\
(0.029)\end{array}$ & $\begin{array}{c}-0.011 \\
(0.029)\end{array}$ & $\begin{array}{c}-0.011 \\
(0.029)\end{array}$ & $\begin{array}{c}-0.010 \\
(0.029)\end{array}$ & $\begin{array}{c}-0.011 \\
(0.029)\end{array}$ & $\begin{array}{c}-0.011 \\
(0.029)\end{array}$ \\
\hline Law & $\begin{array}{c}-0.233^{* * *} \\
(0.028)\end{array}$ & $\begin{array}{c}-0.234^{* * *} \\
(0.028)\end{array}$ & $\begin{array}{c}-0.234^{* * *} \\
(0.028)\end{array}$ & $\begin{array}{c}-0.232^{* * *} \\
(0.028)\end{array}$ & $\begin{array}{c}-0.232^{* * *} \\
(0.028)\end{array}$ & $\begin{array}{c}-0.230^{* * *} \\
(0.028)\end{array}$ \\
\hline \multirow[t]{2}{*}{ Honors*Law } & $\begin{array}{l}0.174^{* * *} \\
(0.045)\end{array}$ & $\begin{array}{l}0.178^{* * *} \\
(0.045)\end{array}$ & $\begin{array}{l}0.176^{* * *} \\
(0.045)\end{array}$ & $\begin{array}{l}0.173^{* * *} \\
(0.045)\end{array}$ & $\begin{array}{l}0.182^{* * *} \\
(0.047)\end{array}$ & $\begin{array}{l}0.173^{\text {*** }} \\
(0.051)\end{array}$ \\
\hline & \multicolumn{6}{|c|}{ Panel 2: Difference-in-differences \& entropy balancing } \\
\hline Honors degree & $\begin{array}{c}0.004 \\
(0.030)\end{array}$ & $\begin{array}{c}0.004 \\
(0.030)\end{array}$ & $\begin{array}{c}0.004 \\
(0.030)\end{array}$ & $\begin{array}{c}0.004 \\
(0.030)\end{array}$ & $\begin{array}{c}0.004 \\
(0.030)\end{array}$ & $\begin{array}{c}0.004 \\
(0.030)\end{array}$ \\
\hline Law & $\begin{array}{c}-0.189^{* * *} \\
(0.045)\end{array}$ & $\begin{array}{c}-0.191^{* * *} \\
(0.044)\end{array}$ & $\begin{array}{c}-0.193^{* * *} \\
(0.043)\end{array}$ & $\begin{array}{c}-0.190^{* * *} \\
(0.043)\end{array}$ & $\begin{array}{c}-0.193^{* * *} \\
(0.041)\end{array}$ & $\begin{array}{c}-0.172^{* * *} \\
(0.043)\end{array}$ \\
\hline Honors degree*Law & $\begin{array}{l}0.130^{* *} \\
(0.054)\end{array}$ & $\begin{array}{l}0.135^{* *} \\
(0.053)\end{array}$ & $\begin{array}{c}0.137^{* *} \\
(0.054)\end{array}$ & $\begin{array}{l}0.130^{* *} \\
(0.053)\end{array}$ & $\begin{array}{c}0.135^{* *} \\
(0.053)\end{array}$ & $\begin{array}{r}0.105^{*} \\
(0.057)\end{array}$ \\
\hline $\mathrm{N}$ & 2,199 & 2,197 & 2,190 & 2,174 & 2,141 & 2,102 \\
\hline High school grade & Yes & Yes & Yes & Yes & Yes & Yes \\
\hline Duration of studies & Yes & Yes & Yes & Yes & Yes & Yes \\
\hline Motivation study choice & Yes & Yes & Yes & Yes & Yes & Yes \\
\hline Parental background & Yes & Yes & Yes & Yes & Yes & Yes \\
\hline Further controls & Yes & Yes & Yes & Yes & Yes & Yes \\
\hline Cohort fixed effects & Yes & Yes & Yes & Yes & Yes & Yes \\
\hline
\end{tabular}

Notes: Robust standard errors are reported in parentheses. The table presents results from difference-indifferences specifications and difference-in-differences combined with entropy balancing specifications comparing law graduates to medicine and pharmacy graduates as control group omitting the best law graduates respectively. Column 1 gives the result presented in table 3, columns 2 and 4 . The best law graduates are omitted from the sample based on their first bar exam score. For instance, law graduates with a score of 15 points or above are excluded from the sample in column 2. Significance levels: ${ }^{*} p<0.10,{ }^{* *} p<0.05,{ }^{* * *} p<0.01$. 
Table A-9: Difference-in-differences \& entropy balancing - alternative control groups

\begin{tabular}{|c|c|c|c|}
\hline & \multicolumn{3}{|c|}{ Difference-in-differences \& entropy balancing } \\
\hline & Med-Pharm & Teaching & Economics \\
\hline & $(1)$ & $(2)$ & $(3)$ \\
\hline & \multicolumn{3}{|c|}{ Log of monthly gross earnings } \\
\hline Honors & $\begin{array}{c}0.004 \\
(0.030)\end{array}$ & $\begin{array}{c}-0.040^{* *} \\
(0.019)\end{array}$ & $\begin{array}{l}0.046^{* *} \\
(0.022)\end{array}$ \\
\hline Law & $\begin{array}{c}-0.189^{* * *} \\
(0.045)\end{array}$ & $\begin{array}{l}0.101^{* * *} \\
(0.036)\end{array}$ & $\begin{array}{c}-0.251^{* * *} \\
(0.038)\end{array}$ \\
\hline Honors*Law & $\begin{array}{l}0.130^{* *} \\
(0.054)\end{array}$ & $\begin{array}{l}0.174^{* * *} \\
(0.048)\end{array}$ & $\begin{array}{c}0.088^{*} \\
(0.050)\end{array}$ \\
\hline $\mathrm{N}$ & 2,199 & 2,648 & 2,997 \\
\hline $\mathrm{R}^{2}$ & 0.150 & 0.160 & 0.150 \\
\hline High school grade & Yes & Yes & Yes \\
\hline Duration of studies & Yes & Yes & Yes \\
\hline Motivation study choice & Yes & Yes & Yes \\
\hline Parental background & Yes & Yes & Yes \\
\hline Further controls & Yes & Yes & Yes \\
\hline Cohort fixed effects & Yes & Yes & Yes \\
\hline
\end{tabular}

Notes: The table presents the results from difference-in-differences combined with entropy balancing estimators, comparing law graduates to economic graduates, and education graduates. Linearized standard errors are reported in parentheses. Each column displays the estimates of obtaining an honors degree in law or being among the best graduates in the respective field (Honors), being a law graduate (Law) and from the interaction term of both variables (Honors*Law). Monthly gross earnings are measured five to six years after graduation. The control variables are measured one year after graduation and include the respondent's gender, high school grade, location of high school (eastern Germany, western Germany, abroad), completion of an apprenticeship before studying, location of university (eastern Germany, western Germany, abroad), age at graduation, child at graduation, duration of studies (in semesters), motivation study choice, and the highest general school degree, job qualifications and employment status of both parents. Significance levels: ${ }^{*} p<$ $0.10,{ }^{* *} p<0.05,{ }^{* * *} p<0.01$. 
Table A-10: Sample attrition

\begin{tabular}{|c|c|c|c|c|}
\hline \multirow[b]{2}{*}{ Field of study } & \multirow[b]{2}{*}{ Honors degree } & \multicolumn{2}{|c|}{$\mathrm{N}$} & \multirow[b]{2}{*}{ Attrition in $\%$} \\
\hline & & Wave 1 & Wave 2 & \\
\hline (1) & (2) & (3) & (4) & (5) \\
\hline \multirow{3}{*}{ Law } & No honors degree & 1,238 & 605 & 51.13 \\
\hline & Honors degree & 462 & 261 & 43.51 \\
\hline & Total & 1,700 & 866 & 49.06 \\
\hline Medicine & No top performance & 1,919 & 1,086 & 43.41 \\
\hline$\&$ & Top performance & 512 & 316 & 38.28 \\
\hline pharmacy & Total & 2431 & 1402 & 42.33 \\
\hline
\end{tabular}

Notes: The table shows how many individuals participated in the first survey waves after graduation, and the number of individuals who also participated in the second wave. 
Table A-11: Sample attrition - likelihood to participate in the second survey wave

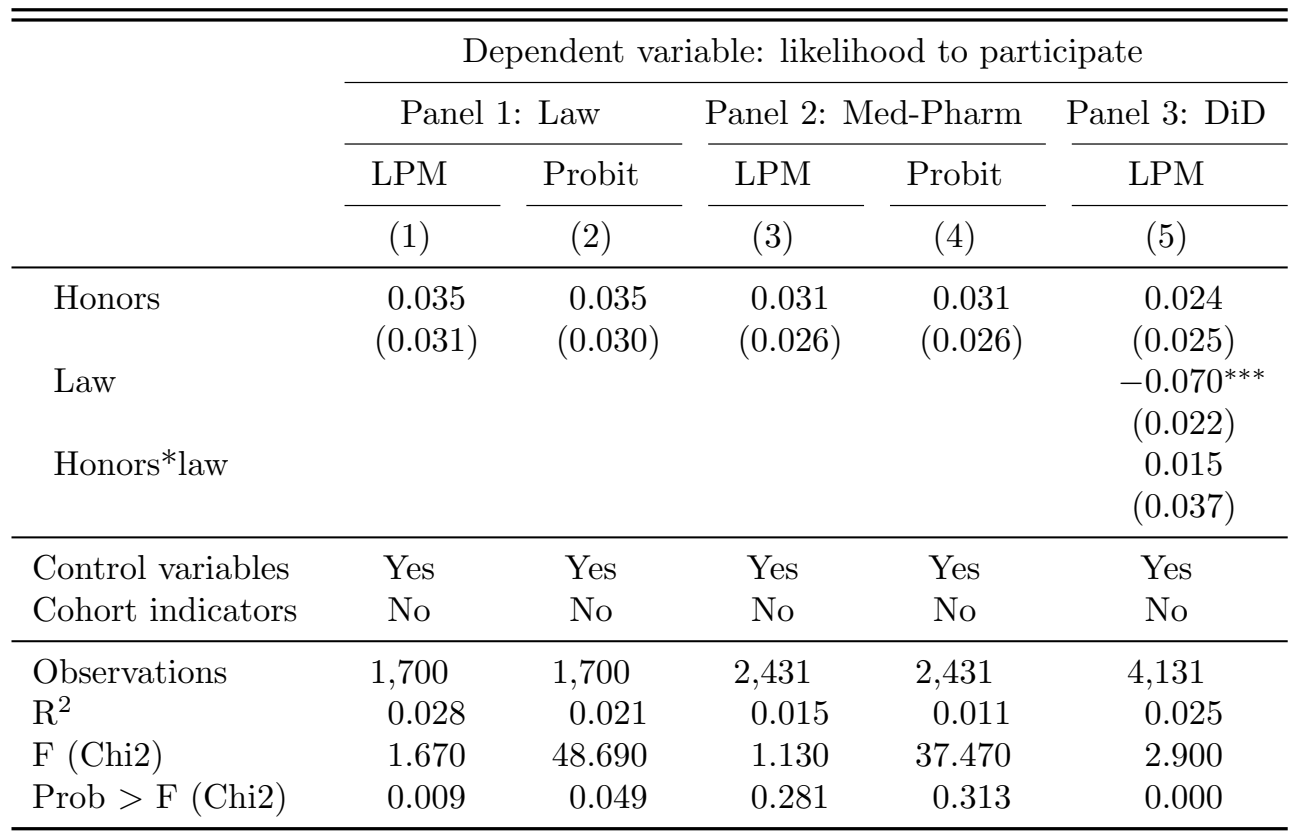

Notes: The dependent variable is an indicator variable equal to one if respondents of the first wave participate in the second wave, and zero otherwise. For the probit models, average partial effects are reported. Standard errors are in parentheses. Robust standard errors are used in columns 1,3 and 5 . Column 5 includes law, medicine and pharmacy graduates. Significance levels: ${ }^{*} p<0.10,{ }^{* *} p<0.05,{ }^{* * *} p<0.01$. 